\title{
Mother-infant attachment and the intergenerational transmission of posttraumatic stress disorder
}

\author{
MICHELLE BOSQUET ENLOW, ${ }^{a, b}$ BYRON EGELAND, ${ }^{c}$ ELIZABETH CARLSON,${ }^{c}$ EMILY BLOOD, ${ }^{a, b}$ AND \\ ROSALIND J. WRIGHT ${ }^{b, d, e}$ \\ ${ }^{a}$ Boston Children's Hospital; ${ }^{b}$ Harvard Medical School; ${ }^{c}$ University of Minnesota; ${ }^{d}$ Brigham \& Women's Hospital; and ${ }^{e}$ Harvard \\ School of Public Health
}

\begin{abstract}
Evidence for the intergenerational transmission of posttraumatic stress disorder (PTSD) is documented in the literature, although the underlying mechanisms are poorly understood. Attachment theory provides a framework for elucidating the ways in which maternal PTSD may increase offspring PTSD vulnerability. The current study utilized two independent prospective data sets to test the hypotheses that (a) maternal PTSD increases the probability of developing an insecure mother-infant attachment relationship and (b) an insecure mother-infant attachment relationship increases the risk of developing PTSD following trauma exposure in later life. In the first study of urban, primarily low-income ethnic/racial minority mothers and infants $(N=45$ dyads), elevated maternal PTSD symptoms at 6 months were associated with increased risk for an insecure, particularly disorganized, mother-infant attachment relationship at 13 months. In the second birth cohort of urban, low-income mothers and children ( $N=96$ dyads), insecure (avoidant or resistant) attachment in infancy was associated in a dose-response manner with increased lifetime risk for a diagnosis of PTSD by adolescence. A history of disorganized attachment in infancy predicted severity of PTSD symptoms, including reexperiencing, avoidance, hyperarousal, and total symptoms, at 17.5 years. In both studies, associations between attachment and PTSD were not attributable to numerous co-occurring risk factors. The findings suggest that promoting positive mother-child relationships in early development, particularly in populations at high risk for trauma exposure, may reduce the incidence of PTSD.
\end{abstract}

Trauma exposure is exceedingly common in the United States, with up to $90 \%$ of adults experiencing at least one traumatic event during their lifetime (Gillespie et al., 2009; Roberts, Gilman, Breslau, Breslau, \& Koenen, 2011). Epidemiological studies have documented that such exposures lead to the development of posttraumatic stress disorder (PTSD) in approximately $10 \%-20 \%$ of women, with higher rates among low-income, ethnic/racial minority, urban populations (Gillespie et al., 2009; Parto, Evans, \& Zonderman, 2011; Roberts et al., 2011; Seng, Kane Low, Sperlich, Ronis, \& Liberzon, 2009). Mothers of young children may be at particularly

\footnotetext{
The authors thank the research staff responsible for data collection and the families whose generous donation of time made this project possible. This research was supported by National Institute of Mental Health Grant K08MH074588 (to M.B.E.); Maternal and Child Health Service Grant MCR-270416, the William T. Grant Foundation, New York, and National Institute of Mental Health Grant MH-40864 (all to B.E.); and National Institute of Environmental Health Sciences Grant R01ES010932 and National Heart, Lung and Blood Institute Grants U01HL072494 and R01HL080674 (all to R.J.W.). During preparation of this manuscript, the authors were supported by Grant K08MH074588 and the Program for Behavioral Science, Department of Psychiatry, Boston Children's Hospital (to M.B.E.), Grant R01HD054850 (to B.E.), and Grant R01MD006086 (to R.J.W.). The content is solely the responsibility of the authors and does not necessarily represent the official views of any of the granting agencies.

Address correspondence and reprint requests to: Michelle Bosquet Enlow, Boston Children's Hospital, 21 Autumn Street, First Floor, Boston, MA 02115; E-mail: michelle.bosquet@childrens.harvard.edu.
}

high risk for PTSD, as epidemiological data indicate that pregnancy and the postnatal period may be times of heightened vulnerability to trauma exposure and the development of PTSD or the reemergence or exacerbation of PTSD symptoms (Loveland Cook et al., 2004; Seedat, Stein, \& Carey, 2005; Seng et al., 2009, 2010), with $14 \%$ of low-income women meeting criteria for PTSD during pregnancy (Loveland Cook et al., 2004; Seng et al., 2009). When maternal PTSD symptoms are considered in addition to PTSD diagnoses, an even higher proportion of mothers are affected (Kimerling, 2003). These findings have significant implications for child mental health in light of mounting evidence that parental PTSD increases offspring risk for psychopathology, including PTSD (Sack, Clarke, \& Seeley, 1995; Scheeringa \& Zeanah, 2001; Yehuda, Halligan, \& Bierer, 2001). The mechanisms responsible for the intergenerational transmission of PTSD are largely unknown. Explicating the processes involved may not only inform intervention strategies among high-risk groups to prevent such intergenerational effects but also provide insight into the etiology of PTSD more generally. Currently, there is little understanding of the preexposure characteristics that influence individuals' vulnerability to developing PTSD, particularly among children and adolescents.

Evidence for transmission of PTSD from parent to child comes from several sources. Scheeringa and Zeanah (2001) noted that children are more likely to develop traumatic stress disorders following trauma exposure if their caregivers also 
develop PTSD in response to the same trauma, prompting the creation of models of "relational PTSD." Younger children appear especially vulnerable to maternal functioning posttrauma exposure (Laor, Wolmer, \& Cohen, 2001). Bogat, DeJonghe, Levendosky, Davidson, and von Eye (2006) found a strong association between maternal and infant traumatic stress symptoms among mother-infant dyads in which the infants had witnessed the mothers experience severe interpersonal violence. Yehuda and colleagues demonstrated that adult offspring of Holocaust survivors with PTSD have higher rates of PTSD than adult offspring of Holocaust survivors without PTSD, even when rates of offspring trauma exposure are similar (Yehuda, Halligan, \& Bierer, 2001; Yehuda, Schmeidler, Giller, Siever, \& Binder-Brynes, 1998; Yehuda, Schmeidler, Wainberg, Binder-Brynes, \& Duvdevani, 1998). In a study comparing Israeli soldiers exposed to combat with and without Holocaust survivor parents, Solomon, Kotler, and Mikulincer (1988) found that offspring of survivors reported a greater number of PTSD symptoms that persisted over a longer period of time. A recent epidemiological investigation in a large population-based sample documented that maternal lifetime posttraumatic stress symptoms predicted adult offsprings' risk of a likely PTSD diagnosis, even when the maternal trauma exposure occurred before the offspring's birth (Roberts et al., 2012). Of note, these data indicate that parental trauma exposure need not occur during the child's lifetime in order to affect the child. Furthermore, research documenting stronger and unique intergenerational trauma effects among mothers compared to fathers and their offspring (Yehuda, Bell, Bierer, \& Schmeidler, 2008) indicates that although genetic factors may contribute to parent-offspring PTSD concordance rates, they are unlikely to be solely responsible. Factors specific to mothers, such as the intrauterine environment during pregnancy and/or the quality of the mother-child relationship, likely also contribute to offspring effects (Yehuda \& Bierer, 2008; Yehuda et al., 2005). Limitations of the research to date include a relative focus on samples with specific forms of trauma (e.g., war trauma; Sack et al., 1995), assessment of offspring in adolescence or adulthood, and reliance on subjective reporting in cross-sectional designs. Therefore, there is a need for prospective studies that examine the impact of maternal PTSD on early childhood outcomes employing observational measures and considering broader definitions of trauma exposure.

Processes involved in the intergenerational transmission of PTSD may begin in the first years of life, when physiological, affective, and behavioral systems involved in self-regulation are established (Barker, 2001; Seckl, 2001; Yehuda \& Bierer, 2008). Difficulties with self-regulation, which is the ability to modify the intensity and duration of physiological arousal, attention, and affective states in order to (a) protect oneself from becoming overwhelmed by stimulation or disorganized by one's own feelings, (b) modulate one's emotional expressions, and (c) organize complex behaviors involved in social interactions (National Research Council and Institute of Medicine, 2000; Sroufe, Egeland, Carlson, \& Collins, 2005), may be central in the etiology of PTSD. The diagnostic criteria for PTSD, including heightened arousal (e.g., irritability, angry outbursts, concentration difficulties, hypervigilance), reexperiencing of traumatic events (e.g., flashbacks, intense psychological distress and/or physiological reactivity upon exposure to traumatic reminders), and avoidance and numbing (e.g., restricted range of affect, anhedonia, feeling detached from others), suggest serious disruptions in physiological, emotional, and behavioral regulation. Studies assessing individuals immediately following trauma exposure have found that those demonstrating increased emotional reactivity and dissociation are at increased risk of developing PTSD in the ensuing months (Ozer, Best, Lipsey, \& Weiss, 2003; Putnam, 1995; Ursano et al., 1999). Moreover, prolonged distress following trauma has been associated with certain emotion regulation strategies, including high avoidance, blunting coping strategies, difficulty acknowledging emotion, and difficulty accessing social support (Benoit, Bouthillier, Moss, Rousseau, \& Brunet, 2010). Therefore, poor self-regulation, particularly in the context of stress exposure, may represent a critical vulnerability factor for PTSD; alternatively, optimal self-regulation abilities may promote resiliency in the face of trauma.

\section{Insecure Attachment History as a Risk Factor for PTSD}

Attachment theory and related empirical evidence provide one framework for understanding how maternal PTSD may increase offspring vulnerability to PTSD via effects on the development of self-regulatory abilities. According to attachment theory, the ability to self-regulate arises out of the context of the caregiver-child relationship in the first years of life (Sroufe, 1995). Initially, neonates and young infants are focused on maintaining physiological homeostasis and rely on their caregivers as regulators (Loman \& Gunnar, 2010). Physiological stress regulatory systems (e.g., hypothalamicpituitary-adrenal [HPA] system, autonomic nervous system, central nervous system) become organized during the first months through caregiver-infant transactions, with sensitive caregiving promoting effective stress regulation (Loman \& Gunnar, 2010). By 4 to 6 months of age, infants become active participants in the regulation of their arousal and emotional states through their relationships with their caregivers (Sroufe, 1995). By the end of the first year, the attachment relationship is firmly established, and the ability of the relationship to regulate the infant's distress may be observed. During this period, infants begin to show stabilizing patterns of frontal neural activation and predictable behavioral strategies for emotion regulation (Bell \& Fox, 1994; Eisenberg, Spinrad, \& Eggum, 2010). Because of the organizational nature of development, the organization of the dyadic relationship is hierarchically integrated into the self-regulatory system. Thus, disruptions to the attachment relationship may impede the development of optimal self-regulation abilities, and these dis- 
ruptions may then be carried forward throughout development (Eisenberg et al., 2010).

Numerous studies have documented associations between the quality of the mother-infant attachment relationship and self-regulation abilities in later life, particularly in the context of stress regulation. Consistently, relationships classified as "secure" compared to relationships classified as "insecure" have been associated with more adaptive self-regulatory abilities and more optimal physiological and behavioral stress regulation (Eisenberg et al., 2010; Kochanska, Philibet, \& Barry, 2009; Oosterman, De Schipper, Fisher, Dozier, \& Schuengel, 2010). Moreover, an insecure attachment relationship in infancy has been associated with increased child vulnerability to the effects of contextual risk (Wan \& Green, 2009).

\section{Attachment typologies and PTSD risk}

There are theoretical reasons to hypothesize that each type of insecure attachment increases vulnerability to PTSD. Attachment classifications are differentiated by distinct patterns of physiological, affective, and behavioral reactions to stress. These patterns are evident in the Strange Situation (Ainsworth, Blehar, Waters, \& Wall, 1978), a laboratory procedure that elicits attachment-based behaviors via a series of caregiver-infant separations and reunions. Children classified as securely attached tend to have a history of sensitive and responsive caregiving; in the Strange Situation, they seek out their caregivers when distressed and accept and are soothed by the caregiver's reassurances, promoting the development of the child's self-regulatory abilities. Children who have experienced hostility from or rejection by their caregiver when distressed tend to develop an insecure-avoidant attachment relationship, which is manifested in the Strange Situation in attempts to avoid physical contact with and minimize displays of distress in the presence of the caregiver. Children with an insecure-resistant attachment relationship, who tend to have a history of inconsistent care, demonstrate heightened attachment behaviors, including acute vigilance to the caregiver and extreme displays of anger or distress. The secure, insecure-avoidant, and insecure-resistant categories represent organized relational strategies for coping with stress that strategically arose in response to the caregiving milieu: secure by engaging the caregiver to regulate distress, insecure-avoidant by minimizing attachment behaviors to avoid rejection, and insecure-resistant by heightening attachment behaviors to ensure the caregiver's attention. An additional, nonmutually exclusive category, insecure-disorganized/disoriented, represents a breakdown in an organized strategy for coping with stress (Carlson, 1998). Children classified as having an insecure-disorganized/disoriented attachment relationship display behaviors indicative of behavioral disorganization or disorientation, manifested in sequential or simultaneous displays of contradictory behaviors; indices of apprehension, fear, disorientation, and confusion; and anomalous movements and expressions (Main \& Solomon, 1990). The insecure-disorganized/disoriented attachment relationship is hy- pothesized to form when the caregiver is both the "haven of safety" as the infant's primary attachment figure and a "source of fear" (Main \& Hesse, 1990) because of frightening caregiving behaviors (e.g., maltreatment, lack of responsiveness, frightened or dazed facial expressions; Liotti, 1992).

Because insecure-disorganized/disoriented behaviors reflect a breakdown in an organized strategy for coping with stress, trauma exposures may be particularly overwhelming for children with an insecure-disorganized/disoriented attachment history (van IJzendoorn, Schuengel, \& Bakermans-Kranenberg, 1999). Although all forms of insecure attachment have been associated with the development of a range of mental health disorders (Ranson \& Urichuk, 2008), a history of insecure-disorganized/disoriented attachment has been most predictive of more extreme forms of psychopathology in childhood and adolescence (Sroufe et al., 2005; van IJzendoorn et al., 1999; Wan \& Green, 2009). An insecure-disorganized/disoriented attachment history may increase risk specifically for PTSD through dissociative processes that occur during or following trauma exposure. Dissociative symptoms, such as flashback episodes and an inability to recall important aspects of the trauma, are characteristic of PTSD. Moreover, experiencing dissociative symptoms during and in the immediate aftermath of a traumatic event is a strong predictor of subsequent PTSD (Putnam, 1995; Ursano et al., 1999). Attachment theorists have hypothesized that a history of insecure-disorganized/disoriented attachment in infancy increases risk for later dissociative processes because of the psychological adaptations necessary to cope with a frightening caregiver. Infants with an insecure-disorganized/disoriented attachment relationship experience unresolvable conflict - the simultaneously experienced urges to flee from a frightening caregiver and to flee to that same caregiver for comforting (Liotti, 1992; Main \& Hesse, 1990; Sroufe et al., 2005). The infant can only escape such a paradox through psychological means, such as gaps in awareness or "protodissociative experiences," which then become a prototype for later adaptation, particularly under conditions of stress or trauma (Liotti, 1992, 2004; Sroufe et al., 2005). Longitudinal examinations of the developmental sequelae of insecure-disorganized/disoriented attachment have found that it is associated with dissociative symptoms into adolescence and adulthood (Carlson, 1998; Lyons-Ruth, 2008; Ogawa, Sroufe, Weinfield, Carlson, \& Egeland, 1997). Therefore, a history of insecure-disorganized/disoriented attachment may increase vulnerability to PTSD by increasing the likelihood of dissociative processes in response to trauma.

A history of insecure-avoidant or insecure-resistant attachment may also increase PTSD vulnerability. Although both insecure-avoidant and insecure-resistant attachment behaviors are considered adaptive strategies for dyadic regulation within the context of insensitive caregiving, they both form prototypes for self-regulation that may be maladaptive in later relationships (Sroufe et al., 2005). Children with insecure-avoidant attachment histories, for example, show decreased abilities to elicit support from others when distressed. 
Of note, the perception of the availability of social support following trauma exposure has been found to be a protective factor in the development of PTSD (Declercq \& Palmans, 2006). The hypervigilance and extreme distress observed among insecure-resistant infants may indicate an increased likelihood of responding to trauma exposures with intense physiological and emotional reactivity, heightening risk for developing PTSD. Furthermore, studies have demonstrated associations between insecure-avoidant and insecure-resistant histories and depression (Duggal, Carlson, Sroufe, \& Egeland, 2001) and between insecure-resistant histories and anxiety disorders (Colonnesi et al., 2011; Warren, Huston, Egeland, \& Sroufe, 1997). Given the overlap in diagnostic criteria for PTSD, other anxiety disorders, and depression and the high comorbidity among these conditions (Chemtob et al., 2010; Loveland Cook et al., 2004), developmental processes that increase risk for anxiety or depression may also increase risk for PTSD.

There has been very limited research explicitly examining associations between infant attachment history and PTSD. In an urban, low-income sample in which half of the participants were exposed in utero to cocaine, MacDonald and colleagues (2008) demonstrated increased levels of PTSD symptomatology, specifically reexperiencing and avoidance symptoms, among 8-year-old children classified as having an insecuredisorganized/disoriented attachment relationship with their mother at 1 year of age. A history of insecure-disorganized/disoriented attachment was not predictive of symptoms of other anxiety disorders (separation anxiety disorder, generalized anxiety disorder, specific phobias). Of note, the study only assessed current PTSD symptoms and not lifetime PTSD symptoms or diagnoses; furthermore, analyses did not address whether a history of insecure-avoidant or insecure-resistant insecure attachment was associated with PTSD symptoms.

\section{Maternal PTSD and Insecure Mother-Infant Attachment}

Evidence suggests that maternal PTSD may negatively impact the mother-infant relationship. Maternal PTSD symptoms have been associated with greater impairment in mothers' prenatal attachment; distorted, inflexible, negative mental representations of their children; and a range of insensitive caregiving behaviors predictive of insecure attachment (Bar-On et al., 1998; Davies, Slade, Wright, \& Stewart, 2008; Lyons-Ruth \& Block, 1996; Muller-Nix et al., 2004; Schechter et al., 2008, 2005, 2010; Schwerdtfeger \& Nelson Goff, 2007).

\section{Maternal PTSD and attachment typologies}

Just as a history of insecure-disorganized/disoriented attachment may especially increase vulnerability to developing PTSD, exposure to maternal PTSD may particularly increase the risk of developing an insecure-disorganized/disoriented attachment relationship. Researchers seeking to understand the precursors of an insecure-disorganized/disoriented attach- ment relationship have reported associations with maternal loss or trauma and with unresolved states of mind with respect to the loss/trauma (Lyons-Ruth \& Block, 1996; Lyons-Ruth, Yellin, Melnick, \& Atwood, 2003; van IJzendoorn, 1995; van IJzendoorn et al., 1999). The unresolved classification is ascertained via the Adult Attachment Interview (George, Kaplan, \& Main, 1985), a semistructured interview that assesses adult state of mind regarding childhood attachments. Unresolved status is characterized by alterations in consciousness or working memory, which some researchers have likened to psychological mechanisms that occur in PTSD (Fearon \& Mansell, 2001; Liotti, 2004; Turton, Hughes, Fonagy, \& Fainman, 2004). Main and Hesse (1990) have hypothesized that unresolved trauma histories cause mothers to live in a continuing state of fear, leading to "frightening," "frightened," or "anomalous" caregiving behaviors (Jacobvitz, Hazen, \& Riggs, 1997; Schuengel, Bakermans-Kranenburg, \& van IJzendoorn, 1999), as well as withdrawing, negative-intrusive, role-confused, and disoriented responses; affective communication errors; dissociation, massive numbing, or affect intolerance; and hostile behaviors, all of which are hypothesized to engender a conflicted state in the infant, leading to disorganized behaviors (Lyons-Ruth \& Block, 1996; Lyons-Ruth, Bronfman, \& Parsons, 1999). PTSD may be associated with similar behaviors (Stovall-McClough \& Cloitre, 2006). For example, during the reexperiencing of a traumatic memory, a mother may become still or engage in behaviors that may be frightening to her infant or interfere with the mother's abilities to recognize her infant's cues, leading to poor responsiveness (Fearon \& Mansell, 2001; Turton et al., 2004). Some have suggested that typical infant behaviors, such as acute distress and helplessness in response to daily frustrations, may serve as traumatic reminders for mothers with trauma histories, who may respond with increasingly angry and fearful behaviors (Liotti, 2004; Stovall-McClough \& Cloitre, 2006). Such behaviors render the attachment relationship nonfunctional with no protective benefit at the level of infant experience (Lyons-Ruth \& Block, 1996), creating a state of fear in the infant that leads to an insecure-disorganized/disoriented attachment relationship. However, very little research has explicitly tested associations between maternal PSD and mother-infant attachment. In addition, the majority of research examining links between maternal trauma and mother-infant attachment has focused on attachment-related traumatic events. There has been little research examining how other forms of maternal trauma may impact the development of the mother-infant attachment relationship.

The underlying attachment classification (secure, insecure-avoidant, or insecure-resistant) is likely to be insecure (insecure-avoidant or insecure-resistant) given the documented impairments in caregiving among traumatized and PTSD-affected mothers (Bar-On et al., 1998; Lyons-Ruth \& Block, 1996; Schechter et al., 2008, 2010; Yehuda \& Bierer, 2008; Yehuda, Halligan, Grossman, 2001). There is evidence that different types of maternal trauma history may be associated with different patterns of caregiving, in- 
cluding one predominantly hostile and another emotionally withdrawn (Lyons-Ruth \& Block, 1996). The hostile pattern may be exacerbated by the reexperiencing and arousal symptoms of PTSD, whereas the emotionally withdrawn pattern may be driven by the avoidant symptoms of PTSD. Caregiving interactions dominated by hostility are expected to increase the likelihood of the development of an insecureavoidant attachment relationship, and emotionally withdrawn caregiving may lead to an insecure-resistant attachment relationship. In addition, mothers with severe trauma histories have been found to engage in preoccupied and overprotective caregiving behaviors, which have been associated with insecure-resistant mother-infant attachment relationships (BarOn et al., 1998). However, no study has specifically tested associations between maternal PTSD and mother-infant insecure-avoidant/secure/insecure-resistant attachment.

\section{The Current Study}

The goal of the current study was to examine associations among maternal PTSD, mother-infant attachment, and child and adolescent PTSD using two independent prospective longitudinal data sets. As depicted in Figure 1, each data set was used to test a different component of the conceptual model. Two main hypotheses were tested:

Hypothesis 1: Maternal PTSD is associated with an increased likelihood of developing an insecure mother-infant attachment relationship, especially an insecure-disorganized/disoriented attachment relationship.

Hypothesis 2: A history in infancy of an insecure attachment relationship, especially an insecure-disorganized/disoriented attachment relationship, increases the likelihood of developing PTSD during childhood or adolescence following trauma exposure.

Hypothesis 1 was tested in an urban, primarily low-income ethnic/racial minority birth cohort sample followed through the first year of life (Study 1). Hypothesis 2 was tested in a low-income, primarily White birth cohort sample assessed during multiple waves of data collection through adolescence (Study 2). In addition, as detailed below within each study's data analysis plan, several alternative hypotheses were tested to support the main hypotheses. The combination of these two studies allows for an examination of the effects of maternal PTSD on the attachment relationship in early development and of the impact of early attachment history on risk for PTSD in later childhood and adolescence.

\section{Study 1}

\section{Method}

Participants. Participants were mothers and their infants $(N=$ 45 dyads) enrolled in a study of the impact of maternal PTSD on infant physiological, emotional, and behavioral reactivity and regulation. Mothers and infants were recruited from an epidemiological birth-cohort study examining risk factors for asthma development in the Asthma Coalition on Community, Environment, and Social Stress project, an urban, primarily low-income, sample of mixed race/ethnicity (Sternthal et al., 2009; Wright et al., 2008). Mothers were originally recruited from two major hospitals in Boston and three urban community health centers during their first or second trimester of pregnancy between August 2006 and September 2009. Criteria for inclusion in the current study included (a) mother 18 years or older at child's birth and (b) single gestation birth. Exclusion criteria for the current study included (a) non-English speaking and (b) infants at increased risk for regulatory difficulties due to premature birth (gestational age $<32$ weeks), low birth weight $(<5.5 \mathrm{lb})$, congenital abnormalities, or neurological injury (Minde, 2000). In addition, during pregnancy, mothers in the parent study were interviewed about alcohol and cigarette use and were not approached for inclusion in the current study if they endorsed usage above established thresholds ( $\geq 7$ alcoholic drinks/week, smoking $\geq 10$ cigarettes/day; Testa, Quigley, \& Eiden, 2003; Wakschlag, Pickett, Cook, Benowitz, \& Leventhal, 2002). ${ }^{1}$

The study consisted of two assessments approximately 6.5 months apart. Forty-three mother-infant dyads completed both assessments; an additional two dyads completed the second assessment only but provided data for all of the predictor and outcome measures, allowing them to be included in the analyses. Seven additional dyads completed the first but not second assessment and are missing necessary outcome data to be included in the current study. Data are missing because of infant excessive distress requiring early termination of the protocol $(n=1)$, inability of the research staff to recontact the dyad (e.g., because of the participant moving, changing phone number, $n=3$ ) or participant refusal to complete the follow-up assessment because of scheduling conflicts or lack of interest $(n=3)$. There were no differences between dyads who did and did not participate in the second assessment on any of the study predictor variables. Table 1 displays the participant characteristics. All procedures were approved by the relevant institutional review boards, and written informed consent was obtained.

Procedures and measures. Mother-infant dyads completed laboratory assessments when the infants were approximately

1. During the children's first year, mothers were reinterviewed about their use of substances during as well as after the pregnancy. In the current sample, $11.1 \%$ of mothers $(n=5)$ endorsed smoking 10 or more cigarettes per day at some point during pregnancy, with two only prior to pregnancy recognition, two during the first trimester, and one throughout the pregnancy. One mother endorsed averaging one alcoholic drink per day during the first trimester. No mother endorsed alcohol use during the child's first year of life. No mothers endorsed the use of any marijuana, opioids, cocaine/crack, or stimulants at any point during the pregnancy or during the child's first year of life. Substance use was not significantly associated with maternal PTSD or mother-infant attachment variables. 
Study 1

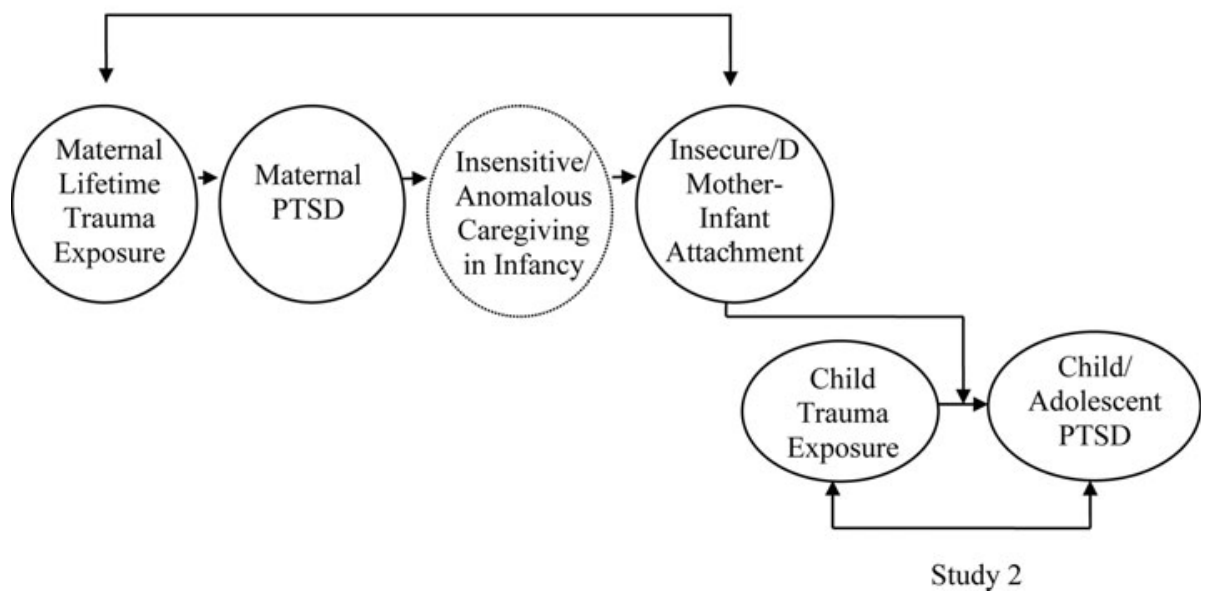

Figure 1. A conceptual model of the mother-infant attachment relationship in the intergenerational transmission of posttraumatic stress disorder (PTSD). Solid circles represent measured constructs, and dotted circles represent unmeasured constructs. D, insecure-disorganized/disoriented.

6 months of age $(M=27.37$ weeks, $S D=1.72)$ and 13 months of age $(M=56.36$ weeks, $S D=4.76)$. Maternal lifetime trauma exposure and psychological symptomatology measures were administered during the 6-month assessment, ${ }^{2}$ and a child trauma exposure questionnaire and the mother-infant attachment procedure were administered during the 13month assessment.

Life Stressor Checklist-Revised (LSC-R). Maternal lifetime exposure to traumatic events was assessed via interview using the LSC-R (Wolfe \& Kimerling, 1997). The LSC-R assesses exposure and reactions to 30 potentially traumatic events (e.g., experiencing or witnessing a serious accident or natural disaster, childhood maltreatment), including experiences particularly relevant to women (e.g., sexual assault, interpersonal violence). The LSC-R has established reliability and validity in diverse populations (Wolfe \& Kimerling, 1997). A maternal lifetime trauma exposure score (range $=0-30$ ) was derived from the number of endorsed events that met DSM-IV PTSD Criterion A, that is, the events during which the mother reported feeling intense helplessness, fear, and/or horror and thinking that she or someone else could be killed or seriously harmed. Mothers were categorized as to whether they had experienced "no trauma exposure" (no events), "low trauma exposure" (one to two events), or "high trauma exposure" (three or more events) during their lifetime.

Posttraumatic Stress Disorder Checklist-Civilian Version $(P C L-C)$. PTSD symptomatology was assessed via interview using the PCL-C (Weathers, Huska, \& Keane, 1991), a 17item measure that reflects DSM-IV symptom criteria for PTSD. Mothers rated each symptom on a 5-point Likert scale in terms of how much it had bothered them in the prior month.

2. Data obtained at the 13-month assessment were used for the two dyads who could not attend the 6-month assessment.
Responses can be used to determine whether participants likely meet DSM-IV criteria for PTSD. Specifically, participants who endorsed being moderately to extremely bothered by one or more reexperiencing symptoms (Cluster B), three or more avoidance/numbing symptoms (Cluster $\mathrm{C}$ ), and two or more hyperarousal symptoms (Cluster D) were classified into an "elevated" PTSD symptoms group, likely meeting DSM-IV criteria for PTSD. Participants who did not meet these criteria were classified into a "nonelevated" PTSD symptoms group. The PCL-C has good test-retest reliability and convergent validity with a number of other PTSD scales and with the Clinician-Administered PTSD Scale, a structured clinical interview for PTSD (Brewin, 2005; Weathers, Keane, \& Davidson, 2001). Internal consistency in this sample was high (Cronbach $\alpha=0.94)$.

Edinburgh Postnatal Depression Scale (EPDS). Maternal depressive symptoms during the prior week were assessed via interview using the 10-item EPDS (Cox, Holden, \& Sagovksy, 1987), a measure specifically designed to address depressive symptoms in the postnatal period. Participants who scored 13 or greater were classified into an "elevated" depressive symptoms group; the remainder were classified into a "nonelevated" depressive symptoms group. The measure has been validated in childbearing women and has demonstrated high internal consistency and validity for detecting major depression in the perinatal period with a cutoff score of 13 (Cox, Chapman, Murray, \& Jones, 1996). Internal consistency in this sample was high (Cronbach $\alpha=0.91)$.

Traumatic Events Screening Inventory-Parent Report Revised (TESI-PRR). Infant lifetime exposure to potentially traumatic events was assessed via maternal report using the TESI-PRR (Ghosh Ippen et al., 2002), an interview measure specifically developed for children ages 0-6 to screen for a wide range of potentially traumatic events (e.g., accidents, 
Table 1. Participant demographic characteristics for the entire sample and by PTSD group for Studies 1 and 2

\begin{tabular}{|c|c|c|c|c|c|c|}
\hline & \multicolumn{3}{|c|}{ Study 1} & & & \\
\hline & \multirow[b]{2}{*}{$\begin{array}{l}\text { Entire Sample } \\
(N=45 \text { dyads })\end{array}$} & \multicolumn{2}{|c|}{ Maternal PTSD Symptoms } & \multicolumn{3}{|c|}{ Study 2} \\
\hline & & $\begin{array}{l}\text { Elevated } \\
(n=12)\end{array}$ & $\begin{array}{l}\text { Nonelevated } \\
\quad(n=33)\end{array}$ & $\begin{array}{l}\text { Entire Sample } \\
(N=96 \text { dyads })\end{array}$ & $\begin{array}{c}\text { PTSD } \\
(n=25)\end{array}$ & $\begin{array}{l}\text { No PTSD } \\
(n=71)\end{array}$ \\
\hline \multicolumn{7}{|l|}{ Maternal variables } \\
\hline Age at child's birth (years) & $27.04(6.30)$ & $28.10(8.08)$ & $26.66(5.62)$ & $20.10(3.11)$ & $20.16(3.37)$ & $20.08(3.04)$ \\
\hline \multicolumn{7}{|l|}{ Marital status ${ }^{a}$} \\
\hline Married & $33.3 \%$ & $25.0 \%$ & $36.4 \%$ & $34.4 \%$ & $24.0 \%$ & $38.0 \%$ \\
\hline Single/separated/divorced & $55.6 \%$ & $66.7 \%$ & $51.5 \%$ & $65.6 \%$ & $76.0 \%$ & $62.0 \%$ \\
\hline \multicolumn{7}{|l|}{ Education at child's birth ${ }^{a}$} \\
\hline Less than high school & $24.4 \%$ & $41.7 \%$ & $18.2 \%$ & $40.6 \%$ & $60.0 \%$ & $33.8 \%$ \\
\hline High school/GED & $15.6 \%$ & $16.7 \%$ & $15.2 \%$ & $40.6 \%$ & $28.0 \%$ & $45.1 \%$ \\
\hline Some college or greater & $46.7 \%$ & $33.3 \%$ & $51.5 \%$ & $17.7 \%$ & $12.0 \%$ & $19.7 \%$ \\
\hline Primiparous & $42.2 \%$ & $16.7 \% *$ & $51.5 \% *$ & $100 \%^{b}$ & $100 \%$ & $100 \%$ \\
\hline \multicolumn{7}{|l|}{ Race } \\
\hline White & $48.9 \%$ & $50.0 \%$ & $48.5 \%$ & $79.2 \%$ & $72.0 \%$ & $81.7 \%$ \\
\hline Black & $37.8 \%$ & $33.3 \%$ & $39.4 \%$ & $14.6 \%$ & $16.0 \%$ & $14.1 \%$ \\
\hline Native American & $0 \%$ & $0 \%$ & $0 \%$ & $6.3 \%$ & $12.0 \%$ & $4.2 \%$ \\
\hline Multiracial & $8.9 \%$ & $0 \%$ & $12.1 \%$ & $0 \%$ & $0 \%$ & $0 \%$ \\
\hline Ethnicity, Hispanic & $24.4 \%$ & $25.0 \%$ & $24.2 \%$ & $0 \%$ & $0 \%$ & $0 \%$ \\
\hline \multicolumn{7}{|l|}{ Child variables } \\
\hline \multicolumn{7}{|l|}{ Race } \\
\hline White & $35.6 \%$ & $16.7 \%$ & $42.4 \%$ & $65.6 \%$ & $52.0 \%$ & $70.4 \%$ \\
\hline Black & $37.8 \%$ & $33.3 \%$ & $39.4 \%$ & $13.5 \%$ & $16.0 \%$ & $12.7 \%$ \\
\hline Asian & $4.4 \%$ & $16.7 \%$ & $0 \%$ & $0 \%$ & $0 \%$ & $0 \%$ \\
\hline Native American & $0 \%$ & $0 \%$ & $0 \%$ & $3.1 \%$ & $4.0 \%$ & $2.8 \%$ \\
\hline Multiracial & $22.2 \%$ & $33.3 \%$ & $18.2 \%$ & $17.7 \%$ & $28.0 \%$ & $14.1 \%$ \\
\hline Ethnicity, Hispanic & $33.3 \%$ & $33.3 \%$ & $33.3 \%$ & $0 \%$ & $0 \%$ & $0 \%$ \\
\hline Gender, male & $55.6 \%$ & $58.3 \%$ & $54.5 \%$ & $44.8 \%$ & $24.0 \% *$ & $52.1 \% *$ \\
\hline Gestational age $^{a}$ (weeks) & $39.02(1.90)$ & $39.38(1.43)$ & $38.89(2.04)$ & $39.79(1.52)$ & $39.83(1.44)$ & $39.78(1.56)$ \\
\hline Birth weight ${ }^{a}(\mathrm{~g})$ & $3382(488)$ & $3410(534)$ & $3371(479)$ & $3305(466)$ & $3253(542)$ & $3323(441)$ \\
\hline
\end{tabular}

Note: The differences between posttraumatic stress disorder (PTSD) groups in both studies were tested using Fisher's exact tests for categorical variables and $t$ tests for continuous variables. The values in parentheses are standard deviations.

${ }^{a}$ In Study 1, the data for marital status and maternal education were missing for $11.1 \%$ and $13.3 \%$ of the mothers, respectively. In Study 2, the data for maternal education and for child gestational age and birth weight were missing for $1.0 \%, 4.2 \%$, and $4.2 \%$ of the dyads, respectively.

Only primiparous women were eligible for enrollment in Study 2.

* Significantly different between PTSD groups at $p<.05$. 
abuse and neglect, witnessing family violence, separation from primary caregiver, attack by an animal; Stover \& Berkowitz, 2005). The TESI-PRR is a modification of the TESIPR, which has demonstrated good psychometric properties (Ford et al., 2000). A trauma exposure score was calculated by summing the number of events to which the infant was exposed. Infants were categorized as to whether they had experienced "no exposure to potentially traumatic events" (no events), "low exposure" (one event), or "high exposure" (two or more events) during their lifetime.

Strange Situation Procedure (SSP). The SSP (Ainsworth et al., 1978) was administered to assess the quality of the motherinfant attachment relationship. The standardized laboratory procedure consists of eight brief episodes designed to activate infant attachment behaviors via increasingly stressful motherinfant separations and reunions. The procedures were videotaped to enable scoring of attachment classification based on the infants' use of the mother as a secure base from which to explore and as a source of comfort when distressed. Motherinfant dyads were scored into one of the three major classifications: secure, insecure-avoidant, or insecure-resistant. Dyads were separately coded for the presence/absence of insecuredisorganized/disoriented attachment using the classification scheme developed by Main and Solomon (1990). Disorganization/disorientation behaviors were rated on a 9-point scale; dyads scoring 5 or higher were coded as meeting criteria for an insecure-disorganized/disoriented classification. An internationally recognized expert in attachment coding (third author), who was blind to the other study data, coded the assessments for insecure-avoidant/secure/insecure-resistant and for insecure-disorganized/disoriented. A second coder also blind to the other study data rated $25 \%$ of the assessments; the two coders achieved $80 \%$ agreement on attachment classifications. For the current analyses, three dichotomous yes/no scores were used: whether the dyad met criteria for one of the major insecure classifications (insecure-avoidant or insecure-resistant vs. secure, regardless of insecure-disorganized/disoriented status), whether the dyad met criteria for an insecuredisorganized/disoriented classification (insecure-disorganized/ disoriented or not insecure-disorganized/disoriented), and whether the dyad met criteria for any insecure classification (insecure-avoidant, insecure-resistant, and/or insecure-disorganized/disoriented vs. secure without insecure-disorganized/ disoriented).

Demographic risk factors. Demographic risk factors assessed include maternal age, marital status, education level, and parity at the child's birth; maternal and child race/ethnicity; and child gender, gestational age, and birth weight. Marital status was dichotomized into married or not married (single, separated, divorced, widowed). Maternal educational attainment was split into three categories: did not graduate high school/ obtain GED, graduated high school/obtained GED, attended at least some college/associate's degree. Parity was dichotomized into primiparous or multiparous. Maternal age (years) and child gestational age (weeks) and birth weight (g) were treated as continuous variables.

\section{Data analysis plan}

A series of analyses were conducted to test the hypothesis that maternal PTSD is associated with an increased likelihood of developing an insecure mother-infant attachment relationship, especially an insecure-disorganized/disoriented attachment relationship (Hypothesis 1). Data presenting rates of maternal trauma exposure and PTSD and depressive symptoms and the associations among these variables are presented. Binary logistic regression analyses tested whether elevated maternal PTSD symptoms at 6 months were associated with increased likelihood of insecure-avoidant or insecureresistant (vs. secure, regardless of insecure-disorganized/disoriented status), insecure-disorganized/disoriented (vs. not insecure-disorganized/disoriented), or any insecure (insecure-avoidant, insecure-resistant, and/or insecure-disorganized/disoriented vs. secure without insecure-disorganized/ disoriented) mother-infant attachment relationship at 13 months. Analyses tested whether demographic risk factors may be responsible for associations between maternal PTSD and mother-infant attachment in several steps. Prior to testing the associations between maternal PTSD symptoms and the mother-infant attachment variables, a series of $t$ tests and Fisher's exact tests were conducted to examine associations between demographic risk factors and maternal PTSD symptoms. Then, each risk factor that demonstrated a significant association with maternal PTSD symptoms was included as a covariate in subsequent analyses.

Analyses were also conducted to determine whether any associations between maternal PTSD and mother-infant attachment may be due to maternal depression effects, as prior research has demonstrated both high rates of comorbidity between depression and PTSD (Chemtob et al., 2010; Kessler, Sonnega, Bromet, Hughes, \& Nelson, 1995), particularly in perinatal women (Loveland Cook et al., 2004), and significant associations between maternal perinatal depression and insecure mother-infant attachment (Atkinson et al., 2000; Martins \& Gaffan, 2000). Specifically, binary logistic regression analyses tested the associations between maternal depressive symptoms and the mother-infant attachment variables. In addition, the associations between maternal PTSD symptoms and the mother-infant attachment variables were examined while controlling for maternal depressive symptoms to test the contribution of maternal PTSD symptoms to mother-infant attachment independent of maternal depressive symptoms.

Binary logistic regression analyses also examined associations between maternal trauma history and the mother-infant attachment variables to assess whether the experience of a traumatic event or the response to the traumatic event (i.e., PTSD symptoms) was more robustly associated with motherinfant attachment quality. Finally, evidence suggests that offspring of parents with PTSD may be at increased risk of 
trauma exposure (Copeland, Keeler, Angold, \& Costello, 2007; Cuevas, Finkelhor, Ormrod, \& Turner, 2009; Roberts et al., 2012; Yehuda, Halligan, \& Grossman, 2001) and that early trauma exposure increases the likelihood of developing an insecure mother-infant attachment relationship (Baer \& Martinez, 2006; Sroufe et al., 2005; Zeanah et al., 1999). Therefore, a series of logistic regression analyses was run to examine whether differential rates of infant trauma exposure among mothers with and without elevated PTSD symptoms may account for associations between maternal PTSD and mother-infant attachment. First, the association between maternal PTSD symptoms and infant trauma history was tested. Second, the associations between infant trauma history and mother-infant attachment classifications were examined. Third, analyses tested whether any significant associations between maternal PTSD symptoms and mother-infant attachment were affected when infant trauma history was included as a covariate. For all analyses, $p<.05$ was considered statistically significant.

\section{Results}

\section{Maternal lifetime trauma exposure and PTSD and depressive symptoms}

Mothers reported experiencing a range of DSM-IV PTSD Criterion A traumatic events during their lifetime $(M=2.69, S D$ $=2.56$, range $=0-10$ ), with $80 \%$ reporting experiencing at least one traumatic event. Specifically, $20 \%(n=9)$ reported no trauma exposure, $33.3 \%(n=15)$ reported low trauma exposure, and $46.7 \%(n=21)$ reported high trauma exposure. The most frequently reported events included having a serious accident or accident-related injury $(26.7 \%)$; witnessing a robbery, mugging, or attack $(20.0 \%)$; being abused or physically attacked after age 16 by someone known to the participant (20.0\%); being robbed, mugged, or attacked (17.8\%); seeing a serious accident $(17.8 \%)$; learning about a traumatic event happening to a loved one (17.8\%); being emotionally abused or neglected (15.6\%); and being abused or physically attacked before age 16 by someone known to the participant $(15.6 \%)$. The majority of traumatic events $(57 \%)$ occurred in childhood or adolescence $(<18$ years of age).

There was significant variability in maternal report of PTSD symptoms, with $26.7 \%$ of participants $(n=12)$ in the elevated PTSD symptoms group. The nonelevated PTSD symptoms group had a mean total PCL-C score of $26.34(S D=7.90)$, and the elevated group had a mean score of $53.67(S D=9.54), t(43)=9.71, p<.001$. There was similar variability in depressive symptom scores, with $26.7 \%$ $(n=12)$ in the elevated depressive symptoms group. The nonelevated depressive symptoms group had a mean total EPDS score of $4.64(S D=3.10)$, and the elevated group had a mean score of $17.58(S D=3.87), t(43)=11.59$, $p<.001$. There was high overlap between elevated PTSD and depressive symptoms groups, with $75 \%$ of mothers with a likely diagnosis of PTSD also having a likely diagnosis of depression, and $75 \%$ of mothers with a likely diagnosis of depression also having a likely diagnosis of PTSD.

In binary logistic regression analyses, greater lifetime trauma exposure was associated with greater likelihood of being in the elevated PTSD symptoms group, unstandardized logistic coefficient, $b=1.49, p=.02$, odds ratio $(O R)=$ $4.44,95 \%$ confidence interval $(\mathrm{CI})=1.25,15.83$. Lifetime trauma exposure was not associated with depressive symptom status $(b=0.83, p=.11, O R=2.29,95 \% \mathrm{CI}=0.83,6.33)$. Specifically, among those who reported no trauma exposure, $0 \%$ were in the elevated range for PTSD symptoms and $11.1 \%$ were in the elevated range for depressive symptoms; among those who reported low trauma exposure, $20 \%$ were in the elevated range for PTSD symptoms and $20 \%$ were in the elevated range for depressive symptoms, and among those who reported high trauma exposure, $42.9 \%$ were in the elevated range for PTSD symptoms and $38.1 \%$ were in the elevated range for depressive symptoms.

\section{Maternal PTSD symptoms and demographic risk characteristics}

Participants were compared on demographic characteristics by maternal PTSD symptom group. As displayed in Table 1, the groups did not differ on maternal age, marital status, education level, maternal race or ethnicity, or child race, ethnicity, gender, gestational age, or birth weight (all $p s>.05$ ) in two-tailed Fisher's exact tests or $t$ tests. Mothers in the elevated PTSD symptoms group were significantly more likely to have more than one child than were mothers in the nonelevated group ( $p=.046$ ). Therefore, maternal parity was included as a covariate in subsequent analyses.

\section{Associations of mother-infant attachment classification with maternal PTSD and depressive symptoms and lifetime trauma exposure}

Table 2 displays the rates of attachment classifications by maternal lifetime trauma history and PTSD and depressive symptom status. Specifically, Table 2 provides the percentage of dyads scored as insecure-avoidant or insecure-resistant (vs. secure, without regard for insecure-disorganized/disoriented classification); the percentage scored as insecure-disorganized/disoriented (vs. not insecure-disorganized/disoriented); and the percentage scored as insecure-avoidant, insecureresistant, and/or insecure-disorganized/disoriented (vs. secure without insecure-disorganized/disoriented). Table 3 shows the rates of specific attachment classifications-secure, insecureavoidant, and insecure-resistant, each divided by insecure-disorganized/disoriented status (insecure-disorganized/disoriented or not insecure-disorganized/disoriented)_-by maternal PTSD symptom status. Of note, $83.3 \%$ of the dyads in the elevated maternal PTSD symptoms group were classified as insecure (insecure-avoidant, insecure-resistant, and/or insecure-disorganized/disoriented), compared to $33.3 \%$ of the dyads in the nonelevated group. 
Table 2. The rates of avoidant or resistant, disorganized, and insecure (avoidant, resistant, and/or disorganized) mother-infant attachment classification by maternal trauma history and PTSD and depressive symptom status in Study $1(N=45)$

\begin{tabular}{|c|c|c|c|}
\hline & \multicolumn{3}{|c|}{ Attachment Classification } \\
\hline & $\begin{array}{l}\text { Avoidant or Resistant } \\
\qquad(n=19)\end{array}$ & $\begin{array}{l}\text { Disorganized }^{b} \\
\quad(n=11)\end{array}$ & $\begin{array}{l}\text { Insecure }^{c} \\
(n=21)\end{array}$ \\
\hline \multicolumn{4}{|l|}{ Maternal lifetime trauma exposure } \\
\hline No trauma exposure $(n=9)$ & $44.4 \%(4)$ & $11.1 \%(1)$ & $44.4 \%(4)$ \\
\hline Low trauma exposure $(n=15)$ & $40.0 \%(6)$ & $20.0 \%(3)$ & $40.0 \%(6)$ \\
\hline High trauma exposure $(n=21)$ & $42.9 \%(9)$ & $33.3 \%(7)$ & $52.4 \%(11)$ \\
\hline \multicolumn{4}{|l|}{ Maternal PTSD symptom status } \\
\hline Nonelevated $(n=33)$ & $33.3 \%(11)$ & $12.1 \%(4)$ & $33.3 \%(11)$ \\
\hline Elevated $(n=12)$ & $66.7 \%(8)$ & $58.3 \%(7)$ & $83.3 \%(10)$ \\
\hline \multicolumn{4}{|l|}{ Maternal depressive symptom status } \\
\hline Nonelevated $(n=33)$ & $36.4 \%(12)$ & $18.2 \%(6)$ & $39.4 \%(13)$ \\
\hline Elevated $(n=12)$ & $58.3 \%(7)$ & $41.7 \%(5)$ & $66.7 \%(8)$ \\
\hline
\end{tabular}

Note: The values in parentheses are frequency counts.

${ }^{a}$ The percentage of participants classified as insecure-avoidant or insecure-resistant (compared to secure, with the insecure-disorganized/disoriented classification not considered).

${ }^{b}$ The percentage of participants classified as insecure-disorganized/disoriented (compared to not insecure-disorganized/disoriented).

${ }^{c}$ The percentage of participants classified as insecure-avoidant, insecure-resistant, and/or insecure-disorganized/disoriented (compared to secure, not insecure-disorganized/disoriented).

A series of binary logistic regression analyses revealed that maternal PTSD symptoms were associated with mother-infant attachment classification. Compared to dyads among mothers in the nonelevated PTSD symptoms group, dyads among mothers in the elevated PTSD symptoms group were significantly more likely to be classified as insecure, whether the insecure classification considered only insecure-avoidant or insecure-resistant $(b=1.56, p=.04, O R$ $=4.77,95 \% \mathrm{CI}=1.05,21.62$ ), or insecure-avoidant, insecure-resistant, and insecure-disorganized/disoriented $(b=$ $2.43, p=.007, O R=11.31,95 \% \mathrm{CI}=1.92,66.73)$. Elevated maternal PTSD symptoms were specifically associated with increased likelihood of an insecure-disorganized/disoriented attachment classification $(b=2.58, p=.005, O R=13.17$, $95 \% \mathrm{CI}=2.19,79.13)$.

Maternal depressive symptoms were not associated with any of the mother-infant attachment classification scores: inse- cure-avoidant/insecure-resistant $(b=0.94, p=.18, O R=$ $2.56,95 \% \mathrm{CI}=0.64,10.24)$, insecure-avoidant/insecure-resistant/insecure-disorganized/disoriented $(b=1.10, p=.13$, $O R=2.99,95 \% \mathrm{CI}=0.73,12.33)$, and insecure-disorganized/disoriented $(b=1.15, p=.13, O R=3.15,95 \% \mathrm{CI}=$ $0.71,13.92)$. Binary logistic regression analyses that simultaneously included both maternal PTSD and depressive symptom status as predictors revealed that, when predicting insecure-avoidant/insecure-resistant attachment, neither variable was significant. However, compared to the prior analyses in which maternal depressive symptoms were not included in predicting insecure-avoidant/insecure-resistant mother-infant attachment, the magnitude of the estimate for PTSD symptoms was not diminished by the inclusion of depressive symptoms ( $b=1.56, p=.12)$ and was much larger than that for depressive symptoms $(b=0.002, p=1.00)$. When predicting insecure-disorganized/disoriented attachment, maternal PTSD

Table 3. Rates of mother-infant attachment classifications (secure, insecure-avoidant, and insecure-resistant by disorganized/not disorganized) by maternal PTSD symptom status for Study 1

\begin{tabular}{|c|c|c|c|c|c|c|}
\hline & \multicolumn{6}{|c|}{ Attachment Classification } \\
\hline & \multicolumn{2}{|c|}{ Secure } & \multicolumn{2}{|c|}{ Insecure-Avoidant } & \multicolumn{2}{|c|}{ Insecure-Resistant } \\
\hline & $\begin{array}{c}\text { Not } \\
\text { Disorganized }\end{array}$ & Disorganized & $\begin{array}{c}\text { Not } \\
\text { Disorganized }\end{array}$ & Disorganized & $\begin{array}{c}\text { Not } \\
\text { Disorganized }\end{array}$ & Disorganized \\
\hline \multicolumn{7}{|l|}{ Maternal PTSD status } \\
\hline Nonelevated symptoms $(n=33)$ & $66.7 \%(22)$ & $0 \%(0)$ & $6.1 \%(2)$ & $3.0 \%(1)$ & $15.2 \%(5)$ & $9.1 \%(3)$ \\
\hline Elevated symptoms $(n=12)$ & $16.7 \%(2)$ & $16.7 \%(2)$ & $8.3 \%(1)$ & $33.3 \%(4)$ & $16.7 \%(2)$ & $8.3 \%(1)$ \\
\hline
\end{tabular}

Note: The values in parentheses are frequency counts. PTSD, posttraumatic stress disorder. 
symptom status ( $b=3.10, p=.02$ ), but not depressive symptom status $(b=-0.78, p=.54)$, was a significant predictor. Similarly, when predicting any insecure (insecure-avoidant, insecure-resistant, and/or insecure-disorganized/disoriented) attachment, maternal PTSD symptom status $(b=2.87, p=$ $.03)$, but not depressive symptom status $(b=-0.62, p=$ $.60)$, emerged as significant.

Maternal lifetime trauma exposure was not significantly associated with any of the mother-infant attachment classification variables: insecure-avoidant/insecure-resistant $(b=$ $-0.01, p=.98, O R=0.99,95 \% \mathrm{CI}=0.46,2.13)$, insecure-avoidant/insecure-resistant/insecure-disorganized/disoriented $(b=0.20, p=.61, O R=1.22,95 \% \mathrm{CI}=0.57$, 2.64), or insecure-disorganized/disoriented ( $b=0.69, p=$ $.18, O R=2.00,95 \% \mathrm{CI}=0.72,5.53)$.

\section{Infant trauma exposure and the association between maternal PTSD and mother-infant attachment}

Across the sample, $35.6 \%(n=16)$ of mothers reported that their infants had not been exposed to any potentially traumatic events, and $31.1 \%(n=14)$ and $33.3 \%(n=15)$ reported that their infants had been exposed to low and high levels of potentially traumatic events, respectively. The most frequently reported events included experiencing a serious medical procedure/life-threatening illness/treatment by a paramedic or in an emergency room/hospitalization overnight (40.0\%), being separated from an important caregiver for several days or under very stressful circumstances $(17.8 \%)$, experiencing a stressor not listed on the TESI-PRR, such as homelessness or witnessing a police raid (11.1\%), and being in a serious accident (8.9\%). In logistic regression analyses, maternal PTSD symptom status did not predict infant trauma history, and infant trauma history did not predict mother-infant attachment, whether attachment was categorized as insecure-avoidant or insecure-resistant versus secure, insecure-disorganized/disoriented versus not insecure-disorganized/disoriented, or insecure-avoidant, insecure-resistant and/or insecure-disorganized/disoriented versus secure not insecure-disorganized/ disoriented (all $p s>.45$ ). Including infant trauma history as a covariate did not diminish the magnitude of the estimate or the significance of maternal PTSD symptom status in any of the binary logistic regression analyses predicting attachment outcomes from maternal PTSD symptom status.

\section{Study 1 discussion}

The results from Study 1 provide evidence for Hypothesis 1. As predicted, elevated maternal PTSD symptoms at 6 months were associated with a greater likelihood of an insecure mother-infant attachment relationship at 13 months. Although maternal trauma exposure was associated with maternal PTSD symptom status, maternal trauma exposure by itself (i.e., without consideration of PTSD symptom status) was not associated with mother-infant attachment classification. Of note, more than half of the trauma exposures the mothers re- ported occurred during their own childhoods. Maternal PTSD symptoms were not associated with any of the assessed demographic risk factors except parity: mothers with elevated PTSD symptoms were more likely than mothers without elevated PTSD symptoms to have more than one child. Maternal PTSD symptom status was not associated with infant trauma exposure history. Including parity and infant trauma exposure history in the models did not reduce the magnitudes of association between maternal PTSD symptoms and mother-infant attachment status. Finally, maternal depressive symptoms were not significantly associated with mother-infant attachment classification, and maternal PTSD symptoms were associated with insecure-disorganized/disoriented and insecure (insecure-avoidant, insecure-resistant, and/or insecure-disorganized/disoriented) mother-infant attachment even after maternal depressive symptoms were considered.

\section{Study 2}

\section{Method}

Participants. The participants were mothers and children ( $N=96$ dyads) drawn from the Minnesota Longitudinal Study of Risk and Adaptation (MLSRA), a prospective birth cohort study of adaptation in low-income families (Sroufe et al., 2005). The original sample consisted of 267 primiparous women recruited during the third trimester of pregnancy from the Minneapolis Department of Public Health Clinic and the Hennepin County General Hospital between 1975 and 1977. Mothers were eligible for the study if the pregnancy was their first pregnancy and if they qualified for public assistance for prenatal care and delivery (i.e., their income was below the official poverty line).

From birth through adolescence, study participants completed multiple assessment batteries. The majority of participant attrition occurred during the first 2 years of the study. One-hundred seventy-five participants completed measures at 17.5 years of age, the final wave of data collection relevant for the current analyses. Of these 175 participants, $96(55 \%)$ indicated that they had experienced one or more traumatic events during their lifetime and were therefore eligible for inclusion in the main analyses of the current study. There were no differences between families who did and did not complete the current study activities on maternal marital status, race/ethnicity, education level, age, or socioeconomic status (SES) at the child's birth. Table 1 displays the participant demographic characteristics. All procedures were approved by the Institutional Review Board of the University of Minnesota, and written informed consent was obtained.

\section{Procedures and measures.}

SSP. At 12 and 18 months, the quality of the mother-infant attachment relationship was measured using the SSP, as described above in Study 1. Assessments were videotaped and coded by independent experienced coders. Two addi- 
tional coders were used to establish coding agreement. Agreement on attachment type (insecure-avoidant/secure/insecure-resistant) with independent rescoring of the entire MLSRA sample was $89 \%$. Disagreements were resolved by the more experienced coder reviewing the videotape.

Available tapes were later scored for disorganized/disoriented behaviors by a coder trained by scale developer Mary Main; a second coder rated $17 \%$ of the total assessments available, with $86 \%$ agreement. Dyads scoring 5 or higher on the disorganized/disoriented scale were coded as meeting criteria for an insecure-disorganized/disoriented classification. Of note, the SSP assessments were originally recorded on reelto-reel tapes. Some assessments were not available for coding of disorganized/disoriented behaviors because the tapes were recycled and used for multiple assessments or because the tape quality was too deteriorated to be viewed by the time the disorganized/disoriented coding scheme was developed. As a result, $24 \%$ of the current sample had insecure-disorganized/ disoriented ratings for both attachment assessments, 52\% had insecure-disorganized/disoriented ratings for one of the two assessments, and $24 \%$ did not have insecure-disorganized/disoriented ratings for either assessment.

Two scores were derived from the attachment classifications. Participants were coded for the number of assessments for which they were classified into one of the main insecure attachment classifications (insecure-avoidant or insecure-resistant), with possible scores ranging from 0 to 2 . Previous research with this cohort has demonstrated that taking into account continuity/discontinuity in attachment classifications in this way improves prediction of later child outcomes (Sroufe et al., 2005). Missing data for disorganized/disoriented behavior ratings did not allow for scoring of participants on the number of assessments for which they met criteria for an insecure-disorganized/disoriented classification. Instead, participants were separately scored for whether they ever met criteria for insecure-disorganized/disoriented attachment classification based on available data from the two assessments, as has been previously done with this cohort (Carlson, 1998).

Kiddie Schedule for Affective Disorders and Schizophrenia $(K-S A D S)$. At 17.5 years of age, the participants were administered the K-SADS (Ambrosini, Metz, Prabucki, \& Lee, 1989; Orvaschel \& Puig-Antich, 1987; Orvaschel, Puig-Antich, Chambers, Tabrizi, \& Johnson, 1982) to assess lifetime history of a range of major psychiatric disorders. For current diagnoses, the version of the K-SADS that was modified for DSM-III-R criteria (Ambrosini et al., 1989) was used. For past disorders, the epidemiological version (Orvaschel \& Puig-Antich, 1987; Orvaschel et al., 1982) was used. Participants who indicated that they had been exposed to at least one traumatic event during their lifetime were administered the PTSD modules. Adequate reliability and validity for the K-SADS modified for DSM-III-R and the epidemiological K-SADS have been demonstrated (Ambrosini et al., 1989; Orvaschel et al., 1982). For the current analyses, participants were categorized into whether they had met criteria for PTSD at any point during their lifetime. Symptom count scores that represented concurrent (i.e., at 17.5 years) total PTSD symptoms and PTSD cluster symptom scores (reexperiencing, avoidance, hyperarousal), weighted for symptom severity, were also calculated.

Co-occurring risk factors. Analyses considered co-occurring risk factors that may account for associations between attachment classification in infancy and mental health in childhood/ adolescence, including demographic factors, life stress exposure, quality of later mother-child dyadic functioning, and child IQ.

Demographic characteristics. Demographic characteristics considered include maternal age, marital status, and education level at the child's birth, SES, maternal and child race, and child gender, gestational age, and birth weight. Marital status was dichotomized into married or not married (single, separated, divorced, widowed). Maternal education level was split into three categories: did not graduate high school/obtain GED, graduated high school, attended at least some college/ associate's degree. SES was calculated at multiple time points as $\mathrm{T}$ scores based on the mean standardized $z$ scores from at least two of three sources: the revised Duncan Socioeconomic Index household score (Duncan, 1961; Stevens \& Featherman, 1981), mother's level of education, and household income. An average lifetime SES score was derived by calculating the mean of available SES scores from the following assessments: 42 months; Grades 1, 2, 3, and 6; and 16 years. Maternal age (years) and child gestational age (weeks) and birth weight (grams) were treated as continuous variables.

Life stress. Over the child's lifetime, the mothers completed repeated administrations of a modified version of the Life Events Scale (LES; Egeland, Breitenbucher, \& Rosenberg, 1980), a measure of exposure to stressful life events. The measure, administered as an interview, rates the occurrence and disruptiveness of 44 events across a variety of areas (e.g., loss/death, health, employment, finances, legal issues, family relations) since the previous assessment. Interrater agreement between three coders was calculated using the equation " 1 - (number of disparate points)/(number of total possible scoring disparities)"; $98 \%$ agreement was achieved. In prior analyses with the current sample, scores on the LES indicative of increased stress exposure were associated with lowered maternal sensitivity, abusive parenting behaviors, and maladaptive parent-child interactions (Egeland et al., 1980; Pianta \& Egeland, 1990). For the current analyses, a single LES score was derived by calculating the mean of available LES scores from the following assessments: 30, 42, 48, 54, and 64 months; Grades 1, 2, 3, and 6; and 16 years.

In addition, when the participants were 16 years old, they provided self-report of their own stress exposures via the Adolescent Life Events Scale, an adaptation of the Adolescent Perceived Events Scale (Compas, Davis, Forsythe, \& Wagner, 
1987). The Adolescent Life Events Scale includes a list of 89 negative, stressful events. Participants were asked to indicate whether each event happened within the past year and then to rate the frequency and impact of each endorsed event. For the current analyses, the total life stress score was used, which summed the endorsed items, weighted for frequency and impact. This scale has a reported test-retest reliability of 0.89 for this age (Compas et al., 1987). The Adolescent Perceived Events Scale has demonstrated high concurrent and predictive validity (Compas et al., 1987) and has been associated with measures of psychological distress and emotional and behavioral problems (Compas et al., 1987).

Quality of the mother-child relationship in childhood and adolescence. When the children were 42 months of age, they were videotaped with their mothers while engaged in four tasks that were difficult enough to require the mothers to use some teaching strategies to enable the child to complete the tasks (Sroufe et al., 2005). Two observers coded maternal and child behaviors on a variety of 7-point scales. For the current analyses, the scale assessing maternal supportive presence was used (Spearman Brown interrater reliability $r=$ .87 , based on 87 participants' scores). Scores on this scale reflect the extent to which the mother expressed positive regard, provided the child emotional support, and expressed calming reassurance when the child experienced difficulty. Quality of caregiving during these tasks has been shown to predict later behavior problems in this sample, accounting for additional variance beyond attachment history (Sroufe et al., 2005).

When the children were 13 years of age, the quality of the mother-child relationship was assessed in a videotaped laboratory procedure consisting of a series of collaborative tasks (jointly creating an antismoking campaign, completion of an object assembly task by the mother while blindfolded and directed by the adolescent, discussion of the possible effects of imaginary events, collaborative Q-sort of the qualities of an ideal person; Sroufe, 1991). Observers coded dyadic behaviors on a variety of 7-point scales; the majority of ratings were based on conferenced data from two coders. The current analyses used a composite emotional support scale that was the mean of two scales (average interrater reliability, $r=$ .62 ), one assessing the freedom the participants had to function naturally and spontaneously within the dyad and the other assessing the degree to which the relationship supported the needs of the individual (Duggal et al., 2001). Because the majority of ratings were based on conferenced data from two coders, the final conferenced data used in the analyses are likely more reliable than indicated by the interrater reliability coefficient. Previous analyses with this sample have demonstrated concurrent and predictive validity of the scales, with significant associations between the dyadic ratings and child emotional health, peer competence, and behavior problems (Sroufe et al., 2005).

Child IQ. When the children were 64 months of age, they were administered a short form of the Wechsler Preschool and Primary Scale of Intelligence (Wechsler, 1967), including the Vocabulary, Block Design, and Animal House subtests. At 96 months, children were administered a short form of the Wechsler Intelligence Scale for Children-Revised (Wechsler, 1974), including the Vocabulary, Similarities, and Block Design subtests. Prorated IQ scores from both administrations $(M=100, S D=15)$ were derived using Sattler's (1992) formulas. The short forms have high reliability and validity, correlate highly with full-scale IQ scores, and are a validated method for assessing IQ in developmental research (Sattler, 1992; White, Campbell, Echeverria, Knox, \& Janulewicz, 2009).

Data analysis plan. A series of analyses were conducted to test the hypothesis that a history in infancy of an insecure attachment relationship, particularly an insecure-disorganized/ disoriented attachment relationship, increases the likelihood of developing PTSD during childhood and adolescence following trauma exposure (Hypothesis 2). Following presentation of descriptive data, binary logistic regression analyses tested associations between an insecure (insecure-avoidant or insecure-resistant, regardless of insecure-disorganized/ disoriented status) or insecure-disorganized/disoriented mother-infant attachment relationship and PTSD by adolescence among trauma-exposed participants. Prior to testing associations between attachment history and PTSD, a series of Fisher's exact tests and $t$ tests were run to examine differences between participants with and without a diagnosis of PTSD on several risk factors. Each risk factor that demonstrated a significant association with PTSD diagnosis was considered as a covariate in analyses examining links between attachment history and PTSD. Finally, given prior research demonstrating as yet unexplained gender differences evident at least by adolescence in the prevalence and presentation of PTSD (Cuffe et al., 1998; Pratchett, Pelcovitz, \& Yehuda, 2010; Seedat et al., 2005; Tolin \& Foa, 2006), exploratory analyses were conducted to test the role of gender in the development of PTSD within the study model. Specifically, the role of gender as a moderator of the association between attachment history and PTSD was examined. For all analyses, $p<.05$ was considered statistically significant.

Data imputation. Because of the longitudinal nature of the study, some participants had missing data for some time points. To take full advantage of the data, methods were used for addressing missing data to retain all eligible participants (i.e., participants who had endorsed prior trauma exposure at the 17.5 year assessment) in the analyses. Missing data in predictor and covariate variables were imputed for the 96 participants with PTSD outcome data using the Markov Chain Monte Carlo method (Shafer, 1997) of multiple imputation, implemented in SAS PROC MI (SAS Version 9.2, SAS Institute, Cary, NC). This method produces unbiased results if the data are missing at random. Data were missing for $12.5 \%$ of the insecure-avoidant/secure/insecure-resistant attachment observations and $24.0 \%$ of the insecure-disorga- 
nized/disoriented attachment observations. Note that the majority of missing insecure-disorganized/disoriented observations were missing because of random factors (e.g., loss of videotape prior to coding). Covariate risk variables were missing data for $0 \%$ to $6 \%$ of observations. Ten data sets were imputed, each with 96 observations. Analyses were conducted on the multiple imputed data sets and then summarized for inference purposes according to the rules developed by Rubin $(1976,1987)$ implemented in SAS PROC MIANALYZE. Results from the imputed data sets did not differ qualitatively from results from the complete-case data set, and both sets produced the same conclusions. In addition, participants who did and did not have sufficient data to rate either insecure-avoidant/secure/insecure-resistant or insecure-disorganized/disoriented attachment classification did not differ significantly on PTSD diagnostic status or any of the demographic variables presented in Table 1. Results for tests of Hypothesis 2 are based on imputed data.

\section{Results}

Rates of trauma exposure, PTSD, and insecure attachment history. Among the 175 participants administered the KSADS at 17.5 years, $96(54.9 \%)$ endorsed experiencing a traumatic event during their lifetime and were thus subsequently administered the PTSD modules. Among these 96 participants, $26.0 \%(n=25 ; 14.3 \%$ of the total assessed sample) endorsed symptoms meeting diagnostic criteria for PTSD at some point during their lives. The age at which participants met criteria for PTSD varied, with a mean age of onset of 12.16 years $(S D=4.12$ years, range $=5.00-17.08$ years) and a mean duration of symptoms of 2.44 years ( $S D$ $=3.39$ years).

Mother-infant attachment history was varied across the sample. Among those reporting prior trauma exposure on the K-SADS, 39.7\% were classified as having a secure (without consideration of insecure-disorganized/disoriented status) attachment relationship at 12 and 18 months, $37.9 \%$ were classified as having an insecure (insecure-avoidant or insecure-resistant) attachment relationship at either 12 or 18 months, and $22.4 \%$ were classified as having an insecure (insecure-avoidant or insecure-resistant) attachment relationship at both 12 and 18 months. In addition, $35.4 \%$ were scored as meeting criteria for an insecure-disorganized/disoriented attachment classification during at least one of the two attachment assessments. Among those securely attached at both time points, $23.6 \%$ met criteria for an insecure-disorganized/disoriented attachment classification; among those insecurely attached at one time point, $31.3 \%$ met criteria for an insecure-disorganized/disoriented attachment classification; among those insecurely attached at both time points, $63.3 \%$ met criteria for an insecure-disorganized/disoriented attachment classification. In the larger sample, neither insecure-avoidant/insecure-resistant nor insecure-disorganized/ disoriented attachment in infancy was associated with en- dorsement of trauma exposure on the K-SADS in binary logistic regression analyses $(p s>.65)$.

PTSD diagnosis and co-occurring risk factors. As displayed in Table 1, among trauma-exposed participants, there was a significantly greater percentage of females in the PTSD group than in the no PTSD group. Participants with and without a lifetime diagnosis of PTSD did not differ on maternal age, marital status, or education at the time of the child's birth, maternal or child race, or child gestational age or birth weight (all $p s>$.05). PTSD diagnosis was also not significantly associated with measures of SES, maternal or adolescent report of life stress, maternal supportive presence at 42 months, dyadic functioning at 13 years, or child IQ at 64 or 96 months (all $p$ s $>.10$ in $t$ test analyses). ${ }^{3}$ With the exception of gender, risk variables were not considered further in analyses.

Attachment history as predictor of PTSD diagnosis. The number of times classified as having an insecure-avoidant or insecure-resistant mother-infant attachment relationship was significantly associated with lifetime risk of PTSD following trauma exposure in a binary logistic regression analysis $(b=0.90, p=.01, O R=2.46,95 \% \mathrm{CI}=1.21,4.99)$. Attachment history was associated in a dose-response pattern with risk of PTSD: $12.3 \%$ of those who were classified as having a secure attachment relationship at both 12 and 18 months, $28.5 \%$ of those who were classified as having an insecure attachment relationship at either 12 or 18 months, and $45.9 \%$ of those who were classified as having an insecure attachment relationship at both 12 and 18 months developed PTSD following trauma exposure.

Having been classified as having an insecure-disorganized/disoriented attachment relationship in infancy was not associated with lifetime PTSD diagnosis following trauma exposure $(b=0.38, p=.47, O R=1.46,95 \% \mathrm{CI}=0.52$, 4.08). In a post hoc binary logistic regression analysis, a continuous measure of disorganization, operationalized as the maximum insecure-disorganized/disoriented score obtained across available Strange Situation assessments, was also not significantly associated with lifetime PTSD diagnosis $(b=$ $0.16, p=.15, O R=1.18,95 \% \mathrm{CI}=0.94,1.47)$. Of note, among individuals who meet criteria for an insecure-disorganized/disoriented attachment rating, those with an underlying secure attachment relationship may function differently from those with an underlying insecure (insecure-avoidant/insecure-resistant) attachment relationship (Lyons-Ruth, Easterbrooks, \& Cibelli, 1997). Therefore, post hoc follow-up analyses tested whether a history of insecure-disorganized/

3. The SES and maternal life stress mean scores were derived from ratings that occurred from early childhood through adolescence. Given that some of the participants who developed PTSD developed the disorder as young as 5 years of age, the SES and maternal life stress analyses were run again only including scores assessed before 5 years of age. Neither SES nor life stress assessed prior to age 5 was predictive of PTSD diagnostic status $(p s>.20)$. 
disoriented attachment conferred risk for PTSD among participants who did not have the potential buffer of an underlying secure attachment history. In a binary logistic regression analysis including (a) number of times insecurely attached, (b) insecure-disorganized/disoriented attachment classification, and (c) the interaction term between number of times insecurely attached and insecure-disorganized/disoriented attachment classification to predict lifetime PTSD diagnosis, the interaction term was not significant $(p=.25)$, suggesting that insecure-disorganized/disoriented attachment classification did not contribute differently to PTSD risk among participants with and without an underlying secure attachment history. When the interaction term was removed, number of times insecurely attached $(b=0.91, p=.02)$, but not insecure-disorganized/disoriented attachment classification ( $b$ $=-0.07, p=.91$ ), was significantly associated with lifetime PTSD diagnosis. Finally, linear regression analyses examined whether insecure-disorganized/disoriented attachment history predicted severity of PTSD symptoms at 17.5 years: a history of insecure-disorganized/disoriented attachment was significantly associated with greater total PTSD symptoms ( $b=4.28, S E=1.45, p=.003)$, as well as greater reexperiencing ( $b=0.86, S E=0.36, p=.02)$, avoidance $(b=1.67$, $S E=0.66, p=.01)$, and hyperarousal $(b=1.76, S E=0.70$, $p=.01$ ) symptoms at 17.5 years.

Gender, trauma exposure, attachment history, and PTSD. Binary logistic regression analyses among the 175 participants administered the K-SADS demonstrated that females were significantly more likely than males to report having been exposed to trauma during their lifetime $(b=0.75, p=.02$, gen$\operatorname{der} O R=2.13,95 \% \mathrm{CI}=1.16,3.91$ ), with $64.6 \%$ of females and $46.2 \%$ of males reporting prior exposure. In logistic regression analyses, males and females did not differ on rates of insecure-avoidant/insecure-resistant or insecure-disorganized/disoriented attachment in infancy $(p s>.15)$.

To determine whether gender moderated the association between insecure-avoidant/insecure-resistant versus secure attachment history and PTSD, a binary logistic regression analysis was run, including gender and number of times insecurely (insecure-avoidant or insecure-resistant) attached in Step 1 and the interaction term between gender and this attachment history term in Step 2. In Step 1, main effects were found for both attachment history $(b=0.95, p=.01$, $O R=2.60,95 \% \mathrm{CI}=1.26,5.36)$ and gender $(b=1.33, p$ $=.02, O R=3.80,95 \% \mathrm{CI}=1.27,11.37)$, with females (35.8\%) more likely than males (14.0\%) to meet lifetime diagnostic criteria for PTSD following trauma exposure. The Gender $\times$ Attachment History interaction term was not significant in Step $2(p=.53)$. These analyses were repeated using insecure-disorganized/disoriented attachment history in place of number of times insecurely attached; the Gender $\times$ Insecure-Disorganized/Disoriented Attachment History interaction term was not significant $(p=.69)$. Similar analyses were then conducted using each of the PTSD symptom scores (reexperiencing, avoidance, hyperarousal, total symptoms) as the dependent variable in linear regression models; again, the Gender $\times$ Insecure-Disorganized/Disoriented Attachment History interaction term was not significant in any of the models (all $p \mathrm{~s}>.35$ ).

\section{Study 2 discussion}

The results from Study 2 provide partial support for Hypothesis 2. As predicted, quality of attachment in infancy was associated with risk for the development of PTSD by adolescence. Specifically, a history of insecure-avoidant or insecure-resistant insecure attachment was associated in a doseresponse pattern with PTSD risk following trauma exposure in childhood or adolescence. Those with a history of insecure attachment at both 12 and 18 months were at greatest risk and those with a history of secure attachment at both time points were at lowest risk for developing PTSD. The association between insecure-avoidant or insecure-resistant insecure attachment history and PTSD was not attributable to several risk factors, including maternal age, marital status, or education at the child's birth, maternal or child race, child gestational age, birth weight, or IQ, quality of maternal-child dyadic functioning in preschool or adolescence, or SES or life stress through adolescence. Contrary to Hypothesis 2, a history of insecure-disorganized/disoriented attachment was not associated with increased lifetime risk of PTSD. However, a history of insecure-disorganized/disoriented attachment was associated with more severe PTSD symptoms at age 17.5 years. Trauma-exposed females were at greater risk than trauma-exposed males of developing PTSD; there was no evidence that gender moderated the association between attachment history and PTSD.

\section{General Discussion}

Evidence suggests that offspring of parents with PTSD are at increased risk of developing PTSD during their lifetime (Baranowsky, Young, Johnson-Douglas, Williams-Keeler, \& McCarrey, 1998; Roberts et al., 2012; Yehuda, Halligan, \& Bierer, 2001; Yehuda, Schmeidler, Giller et al., 1998; Yehuda, Schmeidler, Wainberg et al., 1998). The mechanisms responsible for this intergenerational transmission are poorly understood. The goal of the current study was to test whether the quality of the mother-infant attachment relationship may contribute to the association between maternal and offspring PTSD (Figure 1). Two longitudinal studies were used to test two main hypotheses: (a) maternal PTSD increases risk for the development of an insecure, particularly insecure-disorganized/disoriented, mother-infant attachment relationship. (b) A history of an insecure, particularly insecure-disorganized/disoriented, mother-infant attachment relationship increases a child's vulnerability to developing PTSD in response to later trauma exposure. The results provided some support for both hypotheses, demonstrating significant associations between maternal PTSD and insecure, particularly insecure-disorganized/disoriented, mother-infant attachment 
and between insecure (insecure-avoidant or insecure-resistant) mother-infant attachment history and lifetime risk of PTSD by adolescence. Contrary to our a priori hypothesis, insecure-disorganized/disoriented attachment in infancy was not predictive of later PTSD diagnosis. However, insecuredisorganized/disoriented attachment history was predictive of severity of PTSD symptoms at 17.5 years. Together, the findings suggest that (a) maternal PTSD may increase risk of child and adolescent PTSD through its effects on the quality of the mother-infant attachment relationship and (b) a history of an insecure mother-infant attachment relationship has persistent effects on an individual's vulnerability to developing PTSD in later life.

Associations between maternal PTSD and mother-infant attachment were tested in an urban, primarily low-income, racial/ethnic minority community-based birth cohort followed longitudinally through the children's first year of life (Study 1). The results demonstrated that infants of mothers with elevated PTSD symptoms when the infants were age 6 months were at 4.77 and 13.17 times greater risk of developing an insecure-avoidant or insecure-resistant and an insecure-disorganized/disoriented attachment relationship, respectively, by 13 months of age. Among dyads in the elevated maternal PTSD symptoms group, $66.6 \%$ were classified as insecureavoidant or insecure-resistant and $58.3 \%$ as insecure-disorganized/disoriented; almost the entire group, $83.3 \%$, was classified as insecure-avoidant, insecure-resistant, and/or insecuredisorganized/disoriented. These rates are notably higher than those found in prior research (e.g., 24\% insecure-avoidant or insecure-resistant in typical middle-class North American populations; 30\%-45\% insecure-disorganized/disoriented in clinical and low SES populations; van IJzendoorn et al., 1999), suggesting potent effects of PTSD on the mother-infant attachment relationship.

In a second urban, low-income, primarily White community-based birth cohort (Study 2), analyses examined whether a history of insecure attachment in infancy predicted greater vulnerability to the development of PTSD in childhood or adolescence following trauma exposure. The results demonstrated a significant, dose-response relationship between an insecure (insecure-avoidant or insecure-resistant) attachment in infancy and a PTSD diagnosis by 17.5 years of age, with those insecurely attached at both 12 and 18 months at greatest risk and those securely attached at both time points at lowest risk. Contrary to expectation, a history of insecure-disorganized/ disoriented attachment was not associated with increased lifetime risk for a diagnosis of PTSD; however, a history of insecure-disorganized/disoriented attachment was predictive of more severe PTSD symptoms at 17.5 years of age.

The findings associating insecure-disorganized/disoriented attachment history with PTSD symptom severity in adolescence but not lifetime diagnosis may reflect a nuanced relationship between insecure-disorganized/disoriented attachment history and PTSD. The theories that have purported an increased risk of PTSD among individuals with a history of insecure-disorganized/disoriented attachment have largely relied on the potential role of insecure-disorganized/ disoriented attachment history in dissociative processes (Liotti 1992, 2004; Schore, 2002). Research supports subtypes of PTSD among both children and adults that are characterized by different neurobiological profiles and patterns of emotional dysregulation, with one rarer type consisting of dissociative symptoms and emotional overmodulation and another more common type consisting primarily of hyperarousal, reexperiencing symptoms, and emotional undermodulation (Lanius et al., 2010; Lanius, Brand, Vermetten, Frewen, \& Spiegel, 2012; Stein et al., 2012). A history of insecure-disorganized/disoriented attachment possibly increases risk for trauma-induced psychopathology with strong dissociative features (e.g., dissociative subtypes of PTSD, dissociative disorders, borderline personality disorder) but not for trauma-induced psychopathology without dissociative features, including subtypes of PTSD with minimal dissociative symptoms. Of note, two other studies using the MLSRA cohort found that insecure-disorganized/disoriented attachment in infancy was predictive of childhood and adolescent dissociative symptoms (Carlson, 1998; Ogawa et al., 1997). Because these studies did not require that participants report trauma exposure to be included in analyses, they were able to utilize larger samples (Carlson, $N=157$; Ogawa et al., $N=168$ ), which provided greater power to detect effects. Associations between insecure-disorganized/ disoriented attachment history and PTSD may also depend on the nature and the timing of the trauma exposure that induced PTSD. For example, insecure-disorganized/disoriented may be more likely to predict PTSD in individuals exposed to chronic and severe trauma early in life than in individuals exposed to an acute trauma or to trauma later in life, as early-onset exposure to multiple traumas is more likely to lead to dissociative symptoms (Lanius et al., 2010, 2012; Stein et al., 2012). Finally, the pattern of findings suggests that the overarching attachment history (secure vs. insecure-avoidant or insecure-resistant) may contribute to whether or not an individual develops PTSD following trauma exposure, and an insecure-disorganized/disoriented attachment history may influence the course of PTSD symptoms, including severity and perhaps also type and duration. Recent research suggests that distinct processes are involved in peritraumatic versus persistent dissociative reactions following trauma exposure, with the latter predictive of greater severity and persistence of PTSD symptoms (Werner \& Griffin, 2012). Similarly, the dissociative subtype of PTSD has been associated with more severe and impairing forms of PTSD and with the persistence of dissociative symptoms even after other PTSD symptoms have resolved (Lanius et al., 2010; Stein et al., 2012). Thus, an insecure-disorganized/disoriented attachment history may contribute to the severity and course of PTSD by increasing the likelihood of persistent dissociative reactions. Further research is needed to determine how any of these factors may influence associations between attachment history and later PTSD.

Given a large body of research showing gender differences in the prevalence and presentation of PTSD for reasons that are poorly understood (Pratchett et al., 2010), Study 2 analy- 
ses examined the role of gender in the prediction of lifetime trauma exposure and PTSD and as a moderator of the relationship between mother-infant attachment history and PTSD. Consistent with prior studies of adolescents (Cuffe et al., 1998; Pratchett et al., 2010; Seedat et al., 2005), females reported greater trauma exposure than males $(64.6 \%$ vs. $46.2 \%)$, and females were more likely than males $(35.8 \%$ vs. $14.0 \%$ ) to meet diagnostic criteria for PTSD following trauma exposure. There was no evidence that a history of insecure attachment functioned differently as a risk factor for the development of PTSD among trauma-exposed males and females.

Analyses explored whether differential rates of trauma exposure may have accounted for the significant associations between attachment and PTSD in the two studies. Previous research suggests that offspring of trauma-exposed parents, particularly parents with PTSD, experience traumatic events at higher rates than offspring of non-trauma-exposed/PTSDaffected parents (Copeland et al., 2007; Cuevas et al., 2009; Yehuda, Halligan, \& Grossman, 2001) and that this increased trauma exposure accounts for elevated rates of PTSD among offspring of mothers with PTSD (Roberts et al., 2012). Moreover, trauma exposure in early development increases the probability of an insecure, particularly insecure-disorganized/disoriented, attachment relationship (Baer \& Martinez, 2006; Sroufe et al., 2005; Zeanah et al., 1999). In Study 1, infant trauma exposure was not associated with either maternal PTSD status or attachment classification, and controlling for infant trauma exposure did not affect the magnitudes of association between maternal PTSD and mother-infant insecure or insecure-disorganized/disoriented attachment. Study 2 failed to find an association between attachment history and later trauma exposure. Moreover, the analyses demonstrating significant associations between attachment history and PTSD were limited to participants who reported prior trauma exposure. Thus, the significant associations between attachment history and PTSD were not attributable to higher rates of trauma exposure among infants of mothers with PTSD in Study 1 or among children/adolescents with insecure attachment histories in Study 2.

Study 1 analyses tested whether the associations between maternal PTSD and mother-infant attachment were due to the effects of depression, which is highly comorbid with PTSD (Chemtob et al., 2010; O'Campo et al., 2006). Previous studies have documented elevated rates of insecure attachment among depressed mothers and their infants (Atkinson et al., 2000; Martins \& Gaffan, 2000). In Study 1, mother-infant attachment was associated with maternal PTSD but not maternal depressive symptoms. Of note, studies that have examined associations between maternal depression and mother-infant attachment have reported inconsistent results, with meta-analyses suggesting that the associations are modest (Atkinson et al., 2000; Tharner et al., 2012; van IJzendoorn et al., 1999). Heterogeneity in maternal depression effects may be attributable to differences in severity of illness and the presence of additional psychiatric disorders and other risk factors across samples (Carter, Garrity-Rokous, Chazan-Cohen, Little, \& Briggs-Gowan, 2001; Toth, Rogosch, Sturge-Apple, \& Cicchetti, 2009). There is some evidence that maternal depression in the absence of comorbid psychiatric diagnoses or life adversity (e.g., poverty, dangerous environments) confers limited increased risk to the mother-infant relationship (Carter et al., 2001; Tharner et al., 2012). Generally, studies documenting associations between maternal depression and mother-infant attachment have not assessed maternal trauma history or PTSD, though many of these studies have been conducted with populations at heightened risk for trauma exposure (e.g., urban, low-income). Given the high comorbidity commonly found between PTSD and depression, particularly in perinatal women (Loveland Cook et al., 2004), the positive depression-attachment findings that have been reported in the literature may be attributable, at least in part, to the effects of PTSD, particularly in populations with high rates of trauma exposure.

Several mechanisms may be responsible for disrupting the attachment relationships of mothers with PTSD and their infants. PTSD is associated with serious disturbances in physiological, emotional, and behavioral self-regulation, and selfregulation is fundamental to forming and maintaining a healthy parent-child relationship (Hien, Cohen, \& Campbell, 2005; Schechter \& Willheim, 2009; Schechter et al., 2004, 2011). Self-regulation difficulties likely impede PTSD-affected mothers' abilities to recognize their infants' cues and respond sensitively and, consequently, foster a secure attachment relationship (Schechter \& Willheim, 2009). Maternal trauma exposure and PTSD have been associated with a range of insensitive caregiving behaviors, including increased intrusiveness and hostility, overprotectiveness, restricted affect, emotional withdrawal, frightened/frightening behaviors, and emotional and physical neglect (Bar-On et al., 1998; Goldberg, Benoit, Blokland, \& Madigan, 2003; Jacobvitz, Leon, \& Hazen, 2006; Lyons-Ruth \& Block, 1996; Muller-Nix et al., 2004; Schechter et al., 2008, 2010; Yehuda \& Bierer, 2008; Yehuda, Halligan, \& Grossman, 2001). Mothers with different subtypes of PTSD may exhibit different patterns of caregiving. For example, the subtype of PTSD characterized by dissociative symptoms may be associated with withdrawal, emotional unavailability, and dissociative episodes, whereas the subtype characterized by hyperarousal and reexperiencing symptoms may be associated with intrusive, angry, irritable behaviors. Different parenting behaviors may in turn be associated with different patterns of attachment (e.g., withdrawn $\rightarrow$ insecure-resistant attachment; hostile $\rightarrow$ insecure-avoidant attachment). Some of the characteristic symptoms of PTSD, such as flashbacks, emotional numbing, angry outbursts, and hypervigilance, may be especially likely to increase the probability that a mother will exhibit the anomalous behaviors that increase risk of an insecure-disorganized/disoriented attachment relationship, including disorientation, dissociative episodes, nonresponsiveness, frightening and hostile behaviors, and frightened facial expressions. Caregiving behaviors may be further compromised by the 
use of alcohol and/or drugs, as research has documented that PTSD-affected women are at heightened risk for abusing substances to ameliorate their PTSD symptoms (Chilcoat \& Breslau, 1998; Hien et al., 2010).

An insecure mother-infant attachment relationship that results from repeated exposures to such insensitive caregiving behaviors may then increase the child's PTSD vulnerability by permanently programming the epigenetic expression of genes involved in the physiological stress response, shaping nonoptimal neurological patterns of stress reactivity, and establishing maladaptive emotional and behavioral styles of coping in response to challenge (McGowan et al., 2011; Nolte, Guiney, Fonagy, Mayes, \& Luyten, 2011; Schore, 2002; Weaver, Meaney, \& Szyf, 2006). For example, early caregiving quality has been shown to play a critical role in the programming of the functioning of the HPA axis, with secure attachment predicting more optimal regulation under stress conditions (Gunnar \& Quevedo, 2007, 2008). Moreover, alterations in the normal functioning of the HPA axis have been implicated in increased risk for later psychopathology, including PTSD (Gunnar \& Quevedo, 2008; McFarlane, Barton, Yehuda, \& Wittert, 2011). Nolte and colleagues have suggested that early caregiving experiences influence the neural circuitry of core regions of the brain involved in stress responding such that individuals with an insecure attachment history underrecruit prefrontal brain regions involved in stress regulation and are vulnerable to amygdala hyperactivation. Dysfunctional activity in both the prefrontal cortex and the amygdala have been implicated in PTSD (Aupperle et al., 2012; Etkin \& Wagner, 2007; Garrett et al., 2012). In addition, mothers with PTSD may model numerous behaviors that may increase child risk for PTSD, including fearful affect, hypervigilance, attentional bias to threat, catastrophic interpretations of events, avoidant coping strategies, and poor self-regulation in stressful situations (Nolte et al., 2011).

Internal working models (IWMs) may be involved in associations between maternal PTSD and mother-infant attachment and between attachment history and PTSD. IWMs are conceptualized as emotional, motivational, and cognitive knowledge or representations that shape how the individual views him/herself, others, and the world (Liotti, 2004; Spangler \& Zimmermann, 1999). The specific characteristics of an individual's IWMs are hypothesized to emerge from the quality of early caregiver-child interactions and to have moderate stability over time into adulthood (Carlson, Sroufe, \& Egeland, 2004; Fraley, 2002; Ranson \& Urichuk, 2008). IWMs may have particular influence over individuals' physiological and emotional regulation and interpersonal functioning under stress conditions (Nolte et al., 2011; Spangler \& Schieche, 1998; Spangler \& Zimmermann, 1999).

Maternal PTSD has been associated with insecure maternal IWMs, including unresolved states of mind with respect to loss or trauma in childhood and nonbalanced, distorted representations of their own child (Bakermans-Kranenburg \& van IJzendoorn, 2009; Lieberman, 1999; Schechter et al., $2005,2007)$, both of which have been linked to caregiving behaviors that predict insecure, and particularly insecure-disorganized/disoriented, mother-infant attachment relationships (e.g., hostile-intrusiveness/negativity, disoriented/ frightening behaviors; Schechter et al., 2008). Insecure maternal IWMs have also been associated with lower levels of reflective functioning or mentalization, that is, the ability to conceive of the self and others as social agents whose thoughts, feelings, desires, and behaviors are driven by intentional mental states (Fonagy, Gergely, Jurist, \& Target, 2002; Schechter et al., 2005; Schechter \& Willheim, 2009; Slade, Grienenberger, Bernbach, Levy, \& Locker, 2005). Lower levels of maternal reflective functioning have been found to predict more negative caregiving behaviors, insecure mother-infant attachment, and lower levels of child reflective functioning (Nolte et al., 2011; Grienenberger, Kelly, \& Slade, 2005; Schechter et al., 2005; Slade et al., 2005). Although there have been theoretical arguments for hypothesizing lower levels of reflective functioning abilities among mothers with PTSD, the limited research has not found such a link (Schechter et al., 2005). More research in this area is warranted.

The negative types of IWM representations about the self, others, and the world that arise out of an insecure mother-infant attachment relationship have been hypothesized to increase risk for PTSD (Sandberg, Suess, \& Heaton, 2010). The IWMs associated with insecure attachment histories are characterized by views of the self as helpless, vulnerable, or unlovable, others as unreliable, helpless, or malevolent, and the world as threatening or dangerous (Liotti, 1992, 2004; Sandberg et al., 2010). Representations of the self as vulnerable and helpless and the world as dangerous may increase hypervigilance, distrust, and intrusive recollections following a traumatic event (Sandberg et al., 2010). Feelings of guilt and shame associated with negative representations of the self may interfere with the ability to regulate affect and cope with painful emotions (Sandberg et al., 2010). The inability to process negative emotional experiences may lead to avoidance, which can interfere with recovery (Sandberg et al., 2010). Mental representations of others as rejecting, inconsistent, or traumatizing may influence perceptions of social support and willingness to seek out and accept support (Sandberg et al., 2010). Of note, insecure IWMs are remarkably similar to the types of cognitive schemas that have been associated with PTSD (Elwood \& Williams, 2007; Foa, Ehlers, Clark, Tolin, \& Orsillo, 1999; Liotti, 1992, 2004; Sandberg et al., 2010; Yehuda, Halligan, \& Grossman, 2001). Although no research has specifically examined how IWMs that arise out of the mother-infant attachment relationship influence PTSD risk, findings from numerous adult studies support the hypothesis that attachment style mediates or moderates the relation between trauma exposure and PTSD (Benoit et al., 2010; Besser \& Neria, 2012; Dieperink, Leskela, Thuras, \& Engdahl, 2001; Elwood \& Williams, 2007; Fraley, Fazzari, Bonanno, \& Dekel, 2006; Muller, Sicoli, \& Lemieux, 2000; O'Connor \& Elklit, 2008; Sandberg et al., 2010; Scott \& Babcock, 2010; Stovall-McClough \& Cloitre, 
2006). Moreover, maternal PTSD symptoms have been found to predict child IWM characteristics that parallel PTSD symptoms, including attentional bias to danger and distress and avoidance of and withdrawal from conflicts (Schechter et al., 2007). Thus, the IWMs of both the mother and the child may play critical roles in the intergenerational transmission of PTSD (Lieberman, 1999).

Genetic factors may also play a role in associations between mother-infant attachment and PTSD. For example, there is evidence that maternal unresolved loss or trauma and disrupted maternal affective communication are predictors of insecure-disorganized/disoriented mother-infant attachment among infants with a specific polymorphism of the dopamine receptor D4 (DRD4) gene, suggesting that infants' sensitivity to caregiving quality is modulated by genetic factors (Gervai et al., 2007; van IJzendoorn \& Bakermans-Kranenburg, 2006). Moreover, there is limited evidence that variations in the DRD4 gene are differentially associated with likelihood of unresolved status in response to negative childhood experiences (Bakermans-Kranenburg, van IJzendoorn, Caspers, \& Philibert, 2011) and with severity of PTSD symptoms among trauma survivors (Dragan \& Oniszczenko, 2009). Similarly, the catechol- $O$-methyltransferase Val158Met polymorphism has been associated with insecure-disorganized/disoriented attachment (Luijk et al., 2011) and with PTSD (Valente et al., 2011), possibly by influencing carriers' susceptibility to environmental influences and/or emotional arousal and stress regulatory abilities. Certain genetically based temperamental characteristics, such as behavioral inhibition, may also increase risk for insecure attachment, particularly among infants of anxious mothers, and for PTSD (Myers, VanMeenen, \& Servatius, 2012; Stevenson-Hinde, Shouldice, \& Chicot, 2011). Therefore, there may be multiple genetic polymorphisms that increase risk for both an insecure attachment relationship and for PTSD, particularly under negative environmental conditions.

Finally, maternal PTSD may impact the mother-infant attachment relationship and offspring PTSD vulnerability through contextual risk factors. For example, mothers with PTSD may be at greater risk for experiencing disruptive events, such as job loss, divorce, and exposure to chronic adversities and traumas (Chiu, deRoon-Cassini, \& Brasel, 2011; Roberts et al., 2012). PTSD has also been associated with depressed IQ, lower socioeconomic achievement, and diminished social support (Chiu et al., 2011; De Bellis, Hooper, Spratt, \& Woolley, 2009). The presence of these risk factors may negatively impact caregiving behaviors, increase maternal and child exposures to stress and trauma, and diminish supportive buffers in the child's environment, all increasing risk for an insecure attachment relationship and child and adolescent PTSD (Levendosky, Bogat, Huth-Bocks, Rosenblum, \& von Eye, 2011; Levendosky, Leahy, Bogat, Davidson, \& von Eye, 2006; Nolte et al., 2011; Roberts et al., 2012). The current analyses did not provide evidence that the significant associations were attributable to contextual risk factors. Specifically, in Study 1, associations between maternal PTSD symptoms and mother-infant attachment could not be attributed to maternal age, marital status, education, race/ethnicity, or parity, or child race/ethnicity, gender, gestational age, or birth weight. In Study 2, PTSD diagnosis was not predicted by maternal age, marital status, or education at the time of the child's birth, maternal or child race, child gestational age, birth weight, or IQ, SES or life stress through adolescence, or quality of the mother-child dyadic relationship in later childhood or adolescence. However, unmeasured contextual risk factors may have contributed to the significant associations. Contextual risk factors may also moderate associations. For example, maternal PTSD may be most likely to disrupt caregiving and the mother-infant attachment relationship when the mother has few cognitive, emotional, and financial resources available. Similarly, an insecure mother-infant attachment history may have a more substantial impact on PTSD vulnerability among children and adolescents living in chaotic environments with fewer alternative supportive adults.

The high rates of trauma exposure and PTSD found in Studies 1 and 2 reflect population prevalence rates, particularly in urban, low-income groups (Copeland et al., 2007; Ford, Elhai, Ruggiero, \& Frueh, 2009; Gillespie et al., 2009; Kessler et al., 1995; Parto et al., 2011; Roberts et al., 2011; Seng et al., 2009). These data highlight the public health importance of determining the etiology of PTSD and the processes involved in the intergenerational transmission of PTSD so that appropriate prevention and intervention strategies may be developed. An examination of the timing and type of traumatic exposures that the mothers in Study 1 experienced revealed that the majority occurred years before the child's conception and varied across type, including interpersonal (e.g., abuse, neglect) and noninterpersonal (e.g., accidents) events. To date, much of the research documenting the effects of maternal trauma on child and parenting outcomes has focused on prenatal or postnatal exposures. Furthermore, studies that have considered lifetime trauma exposures have focused almost exclusively on interpersonal traumas, particularly a history of childhood maltreatment, because of theories that such experiences engender specific vulnerabilities that interfere with the ability to provide sensitive caregiving (Fraiberg, Adelson, \& Shapiro, 1975; Schechter et al., 2008; Schwerdtfeger \& Nelson Goff, 2007). If trauma exposures influence the attachment relationship via the disruptive effects of PTSD symptomatology on maternal caregiving behaviors, then any type of trauma that occurs at any point in the mother's life and leads to PTSD may increase the likelihood of an insecure attachment relationship. However, certain trauma histories may present more extreme challenges to the mother-infant relationship among mothers with PTSD, further increasing the likelihood of an insecure attachment relationship. For example, normative displays of infant helplessness, distress, and aggression may be especially threatening and triggering for mothers with PTSD resulting from intimate partner violence, particularly if the infant physically resembles the perpetrator (Schechter et al., 2008, 2010). 
The mother may respond by emotionally and physically withdrawing, becoming hostile or aggressive, dissociating, and engaging in other anomalous maternal behaviors predictive of insecure and particularly disorganized attachment relationships (Schechter et al., 2008, 2010). To date, no study has examined the roles of trauma characteristics, such as type and timing, on mother-infant attachment. Future research should consider a broad, lifetime perspective of trauma and examine how specific characteristics of maternal trauma histories may interact with PTSD to influence caregiving behaviors and the mother-infant attachment relationship to understand more fully intergenerational effects.

The findings of Study 2 suggest a role for an insecure mother-infant attachment history in the etiology of PTSD. Elucidating pretrauma vulnerability factors for PTSD has been highly challenging given the need to conduct prospective studies that enroll a large number of participants prior to trauma exposure and then follow them over a long period of time to ensure that a sufficient number of participants are trauma-exposed and develop PTSD to provide adequate power for analyses. Consequently, the large majority of PTSD studies begin after trauma exposure, anywhere from immediately postexposure (e.g., during hospitalization for an acute injury) to many years postexposure (e.g., adult survivors of childhood maltreatment). Thus, studies examining pretrauma characteristics that may influence PTSD risk have largely relied on retrospective report, which can suffer from recall bias. Moreover, any differences found between traumaexposed individuals who did and did not develop PTSD in such studies may have been due to the effects of the trauma exposure and not to preexisting person characteristics.

The dose-response relationship between insecure attachment history and PTSD risk found in Study 2 suggests that the longer the mother-infant relationship is impaired, the greater the vulnerability to developing PTSD. Conversely, a child's vulnerability to PTSD may decrease if the mother-infant relationship improves. Prior research with this cohort documented that changes in attachment classification between 12 and 18 months were predicted by maternal and environmental characteristics (Sroufe et al., 2005; Vaughn, Waters, Egeland, \& Sroufe, 1979). Mothers in dyads who changed from secure to insecure were found to show little joy, pleasure, or gratification in their interactions with their infants at 6 months (Egeland \& Farber, 1984; Sroufe et al., 2005). Changing from insecure to secure was associated with decreases in stressful life events. Therefore, children's and adolescents' resilience to PTSD may be enhanced by identifying mother-infant dyads marked by low maternal enjoyment or insecure attachment behaviors and offering interventions that decrease maternal life stress and support positive mother-infant interactions. Such interventions may be particularly beneficial among groups at high risk of trauma exposure.

\section{Strengths and limitations}

To our knowledge, Study 1 is the first study to demonstrate associations between maternal PTSD and mother-infant at- tachment status. Study 2 is one of the only studies to prospectively examine the role of pretrauma characteristics in the development of PTSD and is the first to examine associations between mother-infant attachment history and later PTSD diagnosis. The prospective longitudinal design of both studies is unique within PTSD research. The analyses in both studies were enhanced by consideration of numerous risk factors, none of which diminished the strength of the main findings. Both studies utilized low-income, urban samples, appropriate for the study questions given that low-income, urban groups have increased rates of trauma exposure and related psychopathology compared to the general population (Gillespie et al., 2009; Parto et al., 2011; Roberts et al., 2011; Seng et al., 2009). Unlike many of the studies in this area, the samples were drawn from community-based populations rather than from mental health clinics or from populations with specific, identified caregiving risk factors (e.g., prenatal drug exposure, living in a domestic violence shelter, professionally identified mother-infant difficulties), increasing the generalizability of the findings. The current study results may not generalize to populations with greater access to alternative caregivers or additional resources that may buffer or alter the negative effects of trauma exposure or an insecure mother-infant attachment history (Ranson \& Urichuk, 2008).

Because the study hypotheses were tested using data across two studies, the analyses could not definitively assess the proposed conceptual model of the mediating role of the mother-infant attachment relationship in the intergenerational transmission of PTSD. Because of their relatively small sample sizes, the studies may have been underpowered to detect any associations between maternal depressive symptoms or maternal or infant trauma exposure and mother-infant attachment (Study 1) and any moderating effects of gender (Study 2). The small sample size, as well as the lack of consistent insecure-disorganized/ disoriented attachment ratings, decreased the power to detect associations between a history of insecure-disorganized/disoriented attachment and PTSD diagnosis in Study 2, although associations were found between insecure-disorganized/disoriented attachment history and severity of PTSD symptoms at 17.5 years. Although the current findings provide preliminary support for the proposed conceptual model, future studies that are sufficiently powered to test all aspects of the model within the same longitudinal sample may provide more compelling evidence. Participants in both studies may have underreported trauma exposure, as research has demonstrated that retrospective reports tend to underestimate levels of exposure to traumatic events (Copeland et al., 2007). In Study 1, mothers may have been motivated to underreport infant trauma exposures that they were concerned may prompt a report to child protective services on themselves or a family member. In Study 2, the K-SADS PTSD module was only administered to participants who remembered and reported experiencing at least one traumatic event during their lifetime; there may have been eligible participants who were excluded from analyses because they either did not remember or chose not to report a positive trauma history. Study 1 assessed maternal PTSD 
symptoms using the PCL-C, the most frequently used screening instrument for PTSD in research, particularly with women (Brewin, 2005). Future research should assess maternal PTSD using clinical diagnostic measures, such as the Clinician-Administered PTSD Scale (Blake et al., 2000), which may be less vulnerable to under- or overreporting of symptom severity than are symptom-measure questionnaires (Ortega \& Rosenheck, 2000). Future research in this area should also consider inclusion of comprehensive assessment of maternal substance use given that women with PTSD are at heightened risk for substance use (Chilcoat \& Breslau, 1998; Hien et al., 2010), which may impair caregiving behaviors (Cohen, Hien, \& Batchelder, 2008). Although mothers in Study 1 self-reported minimal prenatal and no postnatal substance use, they may have underreported use.

\section{Conclusions}

The current study provides evidence to support the hypothesis that the quality of the mother-infant attachment relationship is an important mechanism contributing to the intergenerational transmission of PTSD noted in the literature. Research is needed to determine the mechanisms by which

\section{References}

Ainsworth, M. D. S., Blehar, M., Waters, E., \& Wall, S. (1978). Patterns of attachment. Hillsdale, NJ: Erlbaum.

Ambrosini, P. J., Metz, C., Prabucki, K., \& Lee, J. (1989). Videotape reliability of the third revised edition of the K-SADS. Journal of the American Academy of Child \& Adolescent Psychiatry, 28, 723-728.

Atkinson, L., Paglia, A., Coolbear, J., Niccols, A., Parker, K. C., \& Guger, S. (2000). Attachment security: A meta-analysis of maternal mental health correlates. Clinical Psychology Review, 20, 1019-1040.

Aupperle, R. L., Allard, C. B., Grimes, E. M., Simmons, A. N., Flagan, T., Behrooznia, M., et al. (2012). Dorsolateral prefrontal cortex activation during emotional anticipation and neuropsychological performance in posttraumatic stress disorder. Archives of General Psychiatry, 69, 360-371.

Baer, J. C., \& Martinez, C. D. (2006). Child maltreatment and insecure attachment: A meta-analysis. Journal of Reproductive and Infant Psychology, 24, 187-197.

Bakermans-Kranenburg, M. J., \& van IJzendoorn, M. H. (2009). The first 10,000 Adult Attachment Interviews: Distributions of adult attachment representations in clinical and nonclinical groups. Attachment \& Human Development, 11, 223-263.

Bakermans-Kranenburg, M. J., van IJzendoorn, M. H., Caspers, K., \& Philibert, R. (2011). DRD4 genotype moderates the impact of parental problems on unresolved loss or trauma. Attachment \& Human Development, 13, 253-269.

Baranowsky, A. B., Young, M., Johnson-Douglas, S., Williams-Keeler, L., \& McCarrey, M. (1998). PTSD transmission: A review of secondary traumatization in Holocaust survivor families. Canadian Psychology, 39, 247-256.

Barker, D. J. (2001). A new model for the origins of chronic disease. Medicine, Health Care and Philosophy, 4, 31-35.

Bar-On, D., Eland, J., Kleber, R. J., Krell, R., Moore, Y., Sagi, A., et al. (1998). Multigenerational perspectives on coping with the Holocaust experience: An attachment perspective for understanding the developmental sequelae of trauma across generations. International Journal of Behavioral Development, 22, 315-338.

Bell, M. A., \& Fox, N. A. (1994). Brain development over the first year of life: Relations between electroencephalographic frequency and coherence and cognitive and affective behaviors. In G. Dawson \& K. W. Fischer (Eds.), Human behavior and the developing brain (pp. 314-345). New York: Guilford Press. maternal PTSD increases risk for an insecure mother-infant attachment relationship and to identify resiliency factors that may compensate for an insecure attachment history in order to inform intervention development. The study findings point to potential targets of intervention, including identifying and treating PTSD-affected women during pregnancy and supporting the development of secure mother-infant attachment relationships, particularly in populations at high risk for trauma exposure. Treatment may include a combination of trauma-focused therapy to address PTSD symptoms and self-regulatory processes and attachment-oriented therapy to address interpersonal difficulties, insecure IWMs, and caregiving behaviors (Liotti, 2004). Developing methods for accurately identifying and treating at-risk women is critical in light of evidence that (a) low-income pregnant women with PTSD are highly unlikely to seek mental health treatment (Loveland Cook et al., 2004; Seng et al., 2009) and (b) if untreated, PTSD is persistent, becoming increasingly intractable over time (Shalev, Bonne, \& Eth, 1996). By intervening with affected mothers early in their developing relationships with their children and by fostering secure attachments, clinicians may be able to help prevent PTSD from affecting the next generation.
Benoit, M., Bouthillier, D., Moss, E., Rousseau, C., \& Brunet, A. (2010) Emotion regulation strategies as mediators of the association between level of attachment security and PTSD symptoms following trauma in adulthood. Anxiety, Stress, \& Coping, 23, 101-118.

Besser, A., \& Neria, Y. (2012). When home isn't a safe haven: Insecure attachment orientations, perceived social support, and PTSD symptoms among Israeli evacuees under missile threat. Psychological Trauma: Theory, Research, Practice, and Policy, 4, 34-46.

Blake, D. D., Weathers, F. W., Nagy, L. M., Kaloupek, D., Klauminzer, G., Charney, D. S., et al. (2000). Clinician-Administered PTSD Scale (CAPS) instruction manual. Boston: National Center for PTSD.

Bogat, G. A., DeJonghe, E., Levendosky, A. A., Davidson, W. S., \& von Eye, A. (2006). Trauma symptoms among infants exposed to intimate partner violence. Child Abuse and Neglect, 30, 109-125.

Brewin, C. R. (2005). Systematic review of screening instruments for adults at risk for PTSD. Journal of Traumatic Stress, 18, 53-62.

Carlson, E. A. (1998). A prospective study of attachment disorganization/disorientation. Child Development, 69, 1107-1128.

Carlson, E. A., Sroufe, A., \& Egeland, B. (2004). The construction of experience: A longitudinal study of representation and behavior. Child Development, 75, 66-83.

Carter, A. S., Garrity-Rokous, E., Chazan-Cohen, R., Little, C., \& BriggsGowan, M. J. (2001). Maternal depression and comorbidity: Predicting early parenting, attachment security, and toddler social-emotional problems and competencies. Journal of the American Academy of Child \& Adolescent Psychiatry, 40, 18-26.

Chemtob, C. M., Nomura, Y., Rajendran, K., Yehuda, R., Schwartz, D., \& Abramovitz, R. (2010). Impact of maternal posttraumatic stress disorder and depression following exposure to the September 11 attacks on preschool children's behavior. Child Development, 81, 1129-1141.

Chilcoat, H. D., \& Breslau, N. (1998). Investigations of causal pathways between PTSD and drug use disorders. Addictive Behaviors, 23, 827840.

Chiu, K. B., deRoon-Cassini, T. A., \& Brasel, K. J. (2011). Factors identifying risk for psychological distress in the civilian trauma population. Academic Emergency Medicine, 18, 1156-1160.

Cohen, L. R., Hien, D. A., \& Batchelder, S. (2008). The impact of cumulative maternal trauma and diagnosis on parenting behavior. Child Maltreatment, 13, 27-38. 
Colonnesi, C., Draijer, E. M., Stams, G. J. J. M., Van der Bruggen, C. O., Bögels, S. M., \& Noom, M. J. (2011). The relation between insecure attachment and child anxiety: A meta-analytic review. Journal of Clinical Child \& Adolescent Psychology, 40, 630-645.

Compas, B. E., Davis, G. E., Forsythe, C. J., \& Wagner, B. M. (1987). Assessment of major and daily stressful events during adolescence: The Adolescent Perceived Events Scale. Journal of Clinical and Consulting Psychology, 55, 534-541.

Copeland, W. E., Keeler, G., Angold, A., \& Costello, E. J. (2007). Traumatic events and posttraumatic stress in childhood. Archives of General Psychiatry, 64, 577-584.

Cox, J. L., Chapman, G., Murray, D., \& Jones, P. (1996). Validation of the Edinburgh Postnatal Depression Scale (EPDS) in non-postnatal women. Journal of Affective Disorders, 39, 185-189.

Cox, J. L., Holden, J. M., \& Sagovksy, R. (1987). Detection of postnatal depression: Development of the 10-item Edinburgh Postnatal Depression Scale. British Journal of Psychiatry, 150, 782-786.

Cuevas, C. A., Finkelhor, D., Ormrod, R., \& Turner, H. (2009). Psychiatric diagnosis as a risk marker for victimization in a national sample of children. Journal of Interpersonal Violence, 24, 636-652.

Cuffe, S. P., Addy, C. L., Garrison, C. Z., Waller, J. L., Jackson, K. L., McKeown, R. E., et al. (1998). Prevalence of PTSD in a community sample of older adolescents. Journal of the American Academy of Child \& Adolescent Psychiatry, 37, 147-154.

Davies, J., Slade, P., Wright, I., \& Stewart, P. (2008). Posttraumatic stress symptoms following childbirth and mothers' perceptions of their infants. Infant Mental Health Journal, 29, 537-554.

De Bellis, M. D., Hooper, S. R., Spratt, E. G., \& Woolley, D. P. (2009). Neuropsychological findings in childhood neglect and their relationships to pediatric PTSD. Journal of the International Neuropsychological Society, 15, 868-878.

Declercq, F., \& Palmans, V. (2006). Two subjective factors as moderators between critical incidents and the occurrence of posttraumatic stress disorders: "Adult attachment" and "perception of social support." Psychology and Psychotherapy: Theory, Research and Practice, 79, 323-337.

Dieperink, M., Leskela, J., Thuras, P., \& Engdahl, B. (2001). Attachment style classification and posttraumatic stress disorder in former prisoners of war. American Journal of Orthopsychiatry, 71, 374-378.

Dragan, W. L., \& Oniszczenko, W. (2009). The association between dopamine D4 receptor exon III polymorphism and intensity of PTSD symptoms among flood survivors. Anxiety, Stress, \& Coping, 22, 483-495.

Duggal, S., Carlson, E. A., Sroufe, A., \& Egeland, B. (2001). Depressive symptomatology in childhood and adolescence. Development and Psychopathology, 13, 143-164.

Duncan, O. (1961). A socioeconomic index for all occupations. In A. J. Reiss, Jr. (Ed.), Occupations and social status (pp. 109-138). New York: Free Press.

Egeland, B., Breitenbucher, M., \& Rosenberg, D. (1980). Prospective study of the significance of life stress in the etiology of child abuse. Journal of Consulting and Clinical Psychology, 48, 195-205.

Egeland, B., \& Farber, E. (1984). Infant-mother attachment: Factors related to its development and changes over time. Child Development, 55, 753-771.

Eisenberg, N., Spinrad, T. L., \& Eggum, N. D. (2010). Emotion-related selfregulation and its relation to children's maladjustment. Annual Review of Clinical Psychology, 6, 495-525.

Elwood, L. S., \& Williams, N. L. (2007). PTSD-related cognitions and romantic attachment style as moderators of psychological symptoms in victims of interpersonal trauma. Journal of Social and Clinical Psychology, 26, 1189-1209.

Etkin, A., \& Wagner, T. D. (2007). Functional neuroimaging of anxiety: A meta-analysis of emotional processing in PTSD, social anxiety disorder, and specific phobia. American Journal of Psychiatry, 164, 1476-1488.

Fearon, R. M. P., \& Mansell, W. (2001). Cognitive perspectives on unresolved loss: Insights from the study of PTSD. Bulletin of the Menninger Clinic, 65, 380-396.

Foa, E. B., Ehlers, A., Clark, D. M., Tolin, D. F., \& Orsillo, S. M. (1999). The posttraumatic cognitions inventory (PTCI): Development and validation. Psychological Assessment, 11, 303-314.

Fonagy, P., Gergely, G., Jurist, E., \& Target, M. (2002). Affect regulation, mentalization, and the development of the self. New York: Other Press.

Ford, J. D., Elhai, J. D., Ruggiero, K. J., \& Frueh, B. C. (2009). Refining posttraumatic stress disorder diagnosis: Evaluation of symptoms criteria with the National Survey of Adolescents. Journal of Clinical Psychiatry, 70, 748-755.
Ford, J. D., Racusin, R., Ellis, C. G., Daviss, W. B., Reiser, J., Fleischer, A. et al. (2000). Child maltreatment, other trauma exposure, and posttraumatic symptomatology among children with oppositional defiant and attention deficit-hyperactivity disorders. Child Maltreatment, 5, 205-217.

Fraiberg, S., Adelson, E., \& Shapiro, V. (1975). Ghosts in the nursery: A psychoanalytic approach to the problems of impaired infant-mother relationships. Journal of the American Academy of Child Psychiatry, 14, 387421.

Fraley, R. C. (2002). Attachment stability from infancy to adulthood: Metaanalysis and dynamic modeling of developmental mechanisms. Personality and Social Psychology Review, 6, 123-151.

Fraley, R. C., Fazzari, D. A., Bonanno, G. A., \& Dekel, S. (2006). Attachment and psychological adaptation in high-exposure survivors of the September 11th attack on the World Trade Center. Personality and Social Psychology Bulletin, 32, 538-551.

Garrett, A. S., Carrion, V., Kletter, H., Karchemskiy, A., Weems, C. F., \& Reiss, A. (2012). Brain activation to facial expressions in youth with PTSD symptoms. Depression and Anxiety, 29, 449-459.

George, C., Kaplan, N., \& Main, M. (1985). Adult Attachment Interview protocol. Unpublished manuscript, University of California, Berkeley.

Gervai, J., Novak, A., Lakatos, K., Toth, I., Danis, I., Ronai, Z., et al. (2007). Infant genotype may moderate sensitivity to maternal affective communications: Affective disorganization, quality of care, and the $D R D 4$ polymorphism. Social Neuroscience, 2, 307-319.

Ghosh Ippen, C., Ford, J., Racusin, R., Acker, M., Bosquet, M., Rogers, K., et al. (2002). Traumatic Events Screening Inventory-Parent report revised. San Francisco, CA: Early Trauma Network and The National Center for PTSD Dartmouth Child Trauma Research Group, Child Trauma Research Project.

Gillespie, C. F., Bradley, B., Mercer, K., Smith, A. K., Conneely, K., Gapen, M., et al. (2009). Trauma exposure and stress-related disorders in inner city primary care patient. General Hospital Psychiatry, 31 505-514.

Goldberg, S., Benoit, D., Blokland, K., \& Madigan, S. (2003). Atypical maternal behavior, maternal representations, and infant disorganized attachment. Development and Psychopathology, 15, 239-257.

Grienenberger, J. F., Kelly, K., \& Slade, A. (2005). Maternal reflective functioning, mother-infant affective communication, and infant attachment: Exploring the link between mental states and observed caregiving behavior in the intergenerational transmission of attachment. Attachment \& $\mathrm{Hu}$ man Development, 7, 99-311.

Gunnar, M., \& Quevedo, K. (2007). The neurobiology of stress and development. Annual Review of Psychology, 58, 145-173.

Gunnar, M. R., \& Quevedo, K. M. (2008). Early care experiences and HPA axis regulation in children: A mechanism for later trauma vulnerability. Progress in Brain Research, 167, 137-149.

Hien, D., Cohen, L., \& Campbell, A. (2005). Is traumatic stress a vulnerability factor for women with substance use disorders? Clinical Psychology Review, 25, 813-823.

Hien, D. A., Jiang, H., Campbell, A. N. C., Hu, M., Miele, G. M., Cohen, L. R., et al. (2010). Do treatment improvements in PTSD severity affect substance use outcomes? A secondary analysis from a randomized clinical trial in NIDA's Clinical Trials Network. American Journal of Psychiatry, 167, 95-101.

Jacobvitz, D., Hazen, N. L., \& Riggs, S. (1997). Disorganized mental processes in mothers, frightened/frightening caregiving, and disoriented/ disorganized behavior in infancy. Paper presented at the symposium conducted at the biennial meeting of the Society for Research in Child Development, Washington, DC.

Jacobvitz, D., Leon, K., \& Hazen, N. (2006). Does expectant mothers' unresolved trauma predict frightened/frightening maternal behavior? Risk and protective factors. Development and Psychopathology, 18, 363-379.

Kessler, R. C., Sonnega, A., Bromet, E., Hughes, M., \& Nelson, C. B. (1995). Posttraumatic stress disorder in the National Comorbidity Survey. Archives of General Psychiatry, 52, 1048-1060.

Kimerling, R. (2003). Epidemiology of PTSD symptoms among California women. Poster presented at the 131st meeting of the American Public Health Association, San Francisco, CA, November.

Kochanska, G., Philibet, R. A., \& Barry, R. A. (2009). Interplay of genes and early mother-child relationship in the development of self-regulation from toddler to preschool age. Journal of Child Psychology and Psychiatry, 50, 1331-1338.

Lanius, R. A., Brand, B., Vermetten, E., Frewen, P. A., \& Spiegel, D. (2012). The dissociative subtype of posttraumatic stress disorder: Rationale, clin- 
ical and neurobiological evidence, and implications. Depression and Anxiety. Advance online publication.

Lanius, R. A., Vermetten, E., Loewenstein, R. J., Brand, B., Schmahl, C., Bremner, J. D., et al. (2010). Emotion modulation in PTSD: Clinical and neurobiological evidence for a dissociative subtype. American Journal of Psychiatry, 167, 640-647.

Laor, N., Wolmer, L., \& Cohen, D. J. (2001). Mothers' functioning and children's symptoms 5 years after a SCUD missile attack. American Journal of Psychiatry, 158, 1020-1026.

Levendosky, A. A., Bogat, G. A., Huth-Bocks, A. C., Rosenblum, K., \& von Eye, A. (2011). The effects of domestic violence on the stability of attachment from infancy to preschool. Journal of Clinical Child and Adolescent Psychology, 40, 398-410.

Levendosky, A. A., Leahy, K. L., Bogat, G. A., Davidson, W. S., \& von Eye, A. (2006). Domestic violence, maternal parenting, maternal mental health, and infant externalizing behavior. Journal of Family Psychology, 20, 544-552.

Lieberman, A. F. (1999). Negative maternal attributions: Effects on toddlers' sense of self. Psychoanalytic Inquiry, 19, 737-756.

Liotti, G. (1992). Disorganized/disoriented attachment in the etiology of the dissociative disorders. Dissociation, 5, 196-204.

Liotti, G. (2004). Trauma, dissociation, and disorganized attachment: Three strands of a single braid. Psychotherapy: Theory, Research, Practice, Training, 41, 472-486.

Loman, M. M., \& Gunnar, M. R. (2010). Early experience and the development of stress reactivity and regulation in children. Neuroscience \& Biobehavioral Reviews, 34, 867-876.

Loveland Cook, C. A., Flick, L. H., Homan, S. M., Campbell, C., McSweeney, M., \& Gallagher, M. E. (2004). Posttraumatic stress disorder in pregnancy: Prevalence, risk factors, and treatment. Obstetrics and Gynecology, 103, 710-717.

Luijk, M. P., Roisman, G. I., Haltigan, J. D., Tiemeier, H., Booth-Laforce, C., van IJzendoorn, M. H., et al. (2011). Dopaminergic, serotonergic, and oxytonergic candidate genes associated with infant attachment security and disorganization? In search of main and interaction effects. Journal of Child Psychology and Psychiatry, 52, 1295-1307.

Lyons-Ruth, K. (2008). Contributions of the mother-infant relationship to dissociative, borderline, and conduct symptoms in young adulthood. Infant Mental Health Journal, 29, 203-218.

Lyons-Ruth, K., \& Block, D. (1996). The disturbed caregiving system: Relations among childhood trauma, maternal caregiving, and infant affect and attachment. Infant Mental Health Journal, 17, 257-275.

Lyons-Ruth, K., Bronfman, E., \& Parsons, E. (1999). Atypical attachment in infancy and early childhood among children at developmental risk. IV. Maternal frightened, frightening, or atypical behavior and disorganized attachment patterns. Monographs of the Society for Research in Child Development, 64, 67-96.

Lyons-Ruth, K., Easterbrooks, M. A., \& Cibelli, C. D. (1997). Infant attachment strategies, infant mental lag, and maternal depressive symptoms: Predictors of internalizing and externalizing problems at age 7. Developmental Psychology, 33, 681-692.

Lyons-Ruth, K., Yellin, C., Melnick, S., \& Atwood, G. (2003). Childhood experiences of trauma and loss have different relations to maternal unresolved and hostile-helpless states of mind on the AAI. Attachment \& Human Development, 5, 330-352.

MacDonald, H. Z., Beeghly, M., Grant-Knight, W., Augustyn, M., Woods, R.W., Cabral, H., et al. (2008). Longitudinal association between infant disorganized attachment and childhood posttraumatic stress symptoms. Development and Psychopathology, 20, 493-508.

Main, M., \& Hesse, E. (1990). Parents' unresolved traumatic experiences are related to infant disorganized attachment status: Is frightened or frightening parental behavior the linking mechanism? In M. M. Greenberg, D. Cicchetti, \& E. M. Cummings (Eds.), Attachment in the preschool years (pp. 161-182). Chicago: University of Chicago Press.

Main, M., \& Solomon, J. (1990). Procedures for identifying infants as disorganized/disoriented during the Ainsworth Strange Situation. In M. T. Greenberg, D. Cicchetti, \& E. M. Cummings (Eds.), Attachment in the preschool years (pp. 121-160). Chicago: University of Chicago Press.

Martins, C., \& Gaffan, E. A. (2000). Effects of early maternal depression on patterns of infant-mother attachment: A meta-analytic investigation. Journal of Child Psychology and Psychiatry, 41, 737-746.

McFarlane, A. C., Barton, C. A., Yehuda, R., \& Wittert, G. (2011). Cortisol response to acute trauma and risk of posttraumatic stress disorder. Psychoneuroendocrinology, 36, 720-727.
McGowan, P. O., Suderman, M., Sasaki, A., Huang, T. C. T., Hallett, M., Meaney, M., et al. (2011). Broad epigenetic signature of maternal care in the brain of adult rats. PLoS One, 6, e14739. doi:10.1371/journal. pone.0014739

Minde, K. (2000). Prematurity and serious medical conditions in infancy: Implications for development, behavior, and intervention. In C. H. Zeanah, Jr. (Ed.), Handbook of infant mental health (2nd ed., pp. 176-194). New York: Guilford Press.

Muller, R. T., Sicoli, L. A., \& Lemieux, K. E. (2000). Relationship between attachment style and posttraumatic stress symptomatology among adults who report the experience of childhood abuse. Journal of Traumatic Stress, 13, 321-332.

Muller-Nix, C., Forcada-Guex, M., Pierrehumbert, B., Jaunin, L., Borghini, A., \& Ansermet, F. (2004). Prematurity, maternal stress and mother-child interactions. Early Human Development, 79, 145-158.

Myers, C. E., VanMeenen, K. M., \& Servatius, R. J. (2012). Behavioral inhibition and PTSD symptoms in veterans. Psychiatry Research, 196, 271-276.

National Research Council and Institute of Medicine. (2000). From neurons to neighborhoods: The science of early childhood development. Washington, DC: National Academy Press.

Nolte, T., Guiney, J., Fonagy, P., Mayes, L. C., \& Luyten, P. (2011). Interpersonal stress regulation and the development of anxiety disorders: An attachment-based developmental framework. Frontiers in Behavioral Neuroscience, 5. Advance online publication.

O'Campo, P., Kub, J., Woods, A., Garza, M., Jones, S., Gielen, A. C., et al. (2006). Depression, PTSD, and comorbidity related to intimate partner violence in civilian and military women. Brief Treatment and Crisis Intervention, 6, 99-110.

O'Connor, M., \& Elklit, A. (2008). Attachment styles, traumatic events, and PTSD: A cross-sectional investigation of adult attachment and trauma. Attachment \& Human Development, 10, 59-71.

Ogawa, J. R., Sroufe, L. A., Weinfield, N. S., Carlson, E. A., \& Egeland, B. (1997). Development and the fragmented self: Longitudinal study of dissociative symptomatology in a nonclinical sample. Development and Psychopathology, 9, 855-879.

Oosterman, M., De Schipper, J. C., Fisher, P., Dozier, M., \& Schuengel, C. (2010). Autonomic reactivity in relation to attachment and early adversity among foster children. Development and Psychopathology, 22, 109-118.

Ortega, A. N., \& Rosenheck, R. (2000). Posttraumatic stress disorder among Hispanic Vietnam veterans. American Journal of Psychiatry, 157, 615-619.

Orvaschel, H., \& Puig-Antich, K. (1987). Schedule for Affective Disorder and Schizophrenia for School-Age Children, epidemiological version. Philadelphia, PA: Medical College of Pennsylvania, Eastern Pennsylvania Psychiatric Institute.

Orvaschel, H., Puig-Antich, J., Chambers, W., Tabrizi, M. A., \& Johnson, R. (1982). Retrospective assessment of prepubertal major depression with the Kiddie-SADS-E. Journal of the American Academy of Child Psychiatry, 21, 392-397.

Ozer, E. J., Best, S. R., Lipsey, T. L., \& Weiss, D. S. (2003). Predictors of posttraumatic stress disorder and symptoms in adults: A meta-analysis. Psychological Bulletin, 129, 52-73.

Parto, J. A., Evans, M. K., \& Zonderman, A. B. (2011). Symptoms of posttraumatic stress disorder among urban residents. Journal of Nervous and Mental Disease, 199, 436-439.

Pianta, R. C., \& Egeland, B. (1990). Life stress and parenting outcomes in a disadvantaged sample: Results from the Mother-Child Interaction Project. Journal of Clinical Child Psychology, 19, 329-336.

Pratchett, L. C., Pelcovitz, M. R., \& Yehuda, R. (2010). Trauma and violence: Are women the weaker sex? Psychiatric Clinics of North America, 33, 465-474.

Putnam, F. W. (1995). Traumatic stress and pathological dissociation. Annals of the New York Academy of Sciences, 29, 708-715.

Ranson, K. E., \& Urichuk, L. J. (2008). The effect of parent-child attachment relationships on child biopsychosocial outcomes: A review. Early Child Development and Care, 178, 129-152.

Roberts, A. L., Galea, S., Austin, S. B., Cerda, M., Wright, R J., Rich-Edwards, J. W., et al. (2012). Posttraumatic stress disorder across two generations: Concordance and mechanisms in a population-based sample. Biological Psychiatry. Advance online publication.

Roberts, A. L., Gilman, S. E., Breslau, J., Breslau, N., \& Koenen, K. C. (2011) Race/ethnic differences in exposure to traumatic events, development of posttraumatic stress disorder, and treatment-seeking for posttraumatic stress disorder in the United States. Psychological Medicine, 41, 71-83. 
Rubin, D. B. (1976). Inference and missing data. Biometrika, 63, 581-592. Rubin, D. B. (1987). Multiple imputation for nonresponse in surveys. New York: Wiley.

Sack, W. H., Clarke, G. N., \& Seeley, J. (1995). Posttraumatic stress disorder across two generations of Cambodian refugees. Journal of the American Academy of Child \& Adolescent Psychiatry, 34, 1160-1166.

Sandberg, D. A., Suess, E. A., \& Heaton, J. L. (2010). Attachment anxiety as a mediator of the relationship between interpersonal trauma and posttraumatic symptomatology among college women. Journal of Interpersonal Violence, 25, 33-49.

Sattler, J. M. (1992). Assessment of children (3rd ed.). San Diego, CA: Author.

Schechter, D. S., Coates, S. W., Kaminer, T., Coots, T., Zeanah, C. H., Davies, M., et al. (2008). Distorted maternal mental representations and atypical behavior in a clinical sample of violence-exposed mothers and their toddlers. Journal of Trauma \& Dissociation, 9, 123-147.

Schechter, D. S., Coots, T., Zeanah, C. H., Davies, M., Coates, S. W., Trabka, K. A., et al. (2005). Maternal mental representations of the child in an inner-city clinical sample: Violence-related posttraumatic stress and reflective functioning. Attachment \& Human Development, 7, 313-331.

Schechter, D. S., Moser, D. A., Wang, Z., Marsh, R., Hao, X., Duan, Y., et al. (2011). An fMRI study of the brain responses of traumatized mothers to viewing their toddlers during separation and play. Social Cognitive and Affective Neuroscience. Advance online publication.

Schechter, D. S., \& Willheim, E. (2009). Disturbances of attachment and parental psychopathology in early childhood. Child and Adolescent Psychiatric Clinics of North America, 18, 665-686.

Schechter, D. S., Willheim, E., Hinojosa, C., Scholfield-Kleinman, K., Turner, J. B., McCaw, J., et al. (2010). Subjective and objective measures of parent-child relationship dysfunction, child separation distress, and joint attention. Psychiatry, 73, 130-144.

Schechter, D. S., Zeanah, C. H., Myers, M. M., Brunelli, S. A., Liebowitz, M. R., Marshall, R.D., et al. (2004). Psychobiological dysregulation in violence-exposed mothers: Salivary cortisol of mothers with young children pre- and postseparation stress. Bulletin of the Menninger Clinic, 68, 319336.

Schechter, D. S., Zygmunt, A., Coates, S. W., Davies, M., Trabka, K. A., McCaw, J., et al. (2007). Caregiver traumatization adversely impacts young children's mental representations on the MacArthur Story Stem Battery. Attachment \& Human Development, 9, 187-205.

Scheeringa, M. S., \& Zeanah, C. H. (2001). A relational perspective on PTSD in early childhood. Journal of Traumatic Stress, 14, 799-815.

Schore, A. N. (2002). Dysregulation of the right brain: A fundamental mechanism of traumatic attachment and the psychopathogenesis of posttraumatic stress disorder. Australian and New Zealand Journal of Psychiatry, 36, 9-30.

Schuengel, C., Bakermans-Kranenburg, M. J., \& van IJzendoorn, M. H. (1999). Frightening maternal behavior linking unresolved loss and disorganized infant attachment. Journal of Consulting and Clinical Psychology, 67, 54-63.

Schwerdtfeger, K. L., \& Nelson Goff, B. S. (2007). Intergenerational transmission of trauma: Exploring mother-infant prenatal attachment. Journal of Traumatic Stress, 20, 39-51.

Scott, S., \& Babcock, J. C. (2010). Attachment as a moderator between intimate partner violence and PTSD symptoms. Journal of Family Violence, $25,1-9$.

Seckl, J. R. (2001). Glucocorticoid programming of the fetus: Adult phenotypes and molecular mechanisms. Molecular and Cellular Endocrinology, 185, 61-71.

Seedat, S., Stein, D. J., \& Carey, P. D. (2005). Post-traumatic stress disorder in women: Epidemiological and treatment issues. Central Nervous System Drugs, 19, 411-427.

Seng, J. S., Kane Low, L. M., Sperlich, M., Ronis, D. L., \& Liberzon, I. (2009). Prevalence, trauma history, and risk for posttraumatic stress disorder among nulliparous women in maternity care. Obstetrics and Gynecology, 114, 839-847.

Seng, J. S., Rauch, S. A. M., Resnick, H., Reed, C. D., King, A., Low, L. K., et al. (2010). Exploring posttraumatic stress disorder symptom profile among pregnant women. Journal of Psychosomatic Obstetrics and Gynaecology, 31, 176-187.

Shafer, J. L. (1997). Analysis of incomplete multivariate data. New York: Chapman \& Hall.

Shalev, A. Y., Bonne, O., \& Eth, S. (1996). Treatment of posttraumatic stress disorder: A review. Psychosomatic Medicine, 58, 165-182.
Slade, A., Grienenberger, J., Bernbach, E., Levy, D., \& Locker, A. (2005) Maternal reflective functioning, attachment, and the transmission gap: A preliminary study. Attachment \& Human Development, 7, 283-298.

Solomon, Z., Kotler, M., \& Mikulincer, M. (1988). Combat-related posttraumatic stress disorder among second-generation Holocaust survivors: Preliminary findings. American Journal of Psychiatry, 145, 865-868.

Spangler, G., \& Schieche, M. (1998). Emotional and adrenocortical responses of infants to the Strange Situation: The differential function of emotional expression. International Journal of Behavioral Development, $22,681-706$.

Spangler, G., \& Zimmermann, P. (1999). Attachment representation and emotion regulation in adolescents: A psychobiological perspective on internal working models. Attachment \& Human Development, 1, 270-290.

Sroufe, J. W. (1991). Assessment of parent-adolescent relationships: Implications for adolescent development. Journal of Family Psychology, 5, $21-45$.

Sroufe, L. A. (1995). Emotional development: The organization of emotional life during the early years. New York: Cambridge University Press.

Sroufe, L. A., Egeland, B., Carlson, E. A., \& Collins, W. A. (2005). The development of the person. New York: Guilford Press.

Stein, D. J., Koenen, K. C., Friedman, M. J., Hill, E., McLaughlin, K. A., Petukhova, M., et al. (2012). Dissociation in posttraumatic stress disorder: Evidence from the World Mental Health Surveys. Biological Psychiatry. Advance online publication.

Sternthal, M. J., Bosquet Enlow, M., Cohen, S., Jacobson Canner, M., Staudenmayer, J., Tsang, K., et al. (2009). Maternal interpersonal trauma and cord blood IgE levels in an inner-city cohort: A life-course perspective. Journal of Allergy and Clinical Immunology, 124, 954-960.

Stevens, G., \& Featherman, D. L. (1981). A revised socioeconomic index of occupational status. Social Science Research, 10, 364-395.

Stevenson-Hinde, J., Shouldice, A., \& Chicot, R. (2011). Maternal anxiety, behavioral inhibition, and attachment. Attachment \& Human Development, 13, 199-215.

Stovall-McClough, K. C., \& Cloitre, M. (2006). Unresolved attachment, PTSD, and dissociation in women with child abuse histories. Journal of Consulting and Clinical Psychology, 74, 219-228.

Stover, C. S., \& Berkowitz, S. (2005). Assessing violence exposure and trauma symptoms in young children: A critical review of measures. Journal of Traumatic Stress, 18, 707-717.

Testa, M., Quigley, B. M., \& Eiden, R. D. (2003). The effects of prenatal alcohol exposure on infant mental development: A meta-analytic review. Alcohol and Alcoholism, 38, 295-304.

Tharner, A., Luijk, M. P., van IJzendoorn, M. H., Bakermans-Kranenburg, M. J., Jaddoe, V. W., Hofman, A., et al. (2012). Maternal lifetime history of depression and depressive symptoms in the prenatal and early postnatal period do not predict infant-mother attachment quality in a large populationbased Dutch cohort study. Attachment \& Human Development, 14, 63-81.

Tolin, D. F., \& Foa, E. (2006). Sex differences in trauma and posttraumatic stress disorder: A quantitative review of 25 years of research. Psychological Bulletin, 132, 959-992.

Toth, S. L., Rogosch, F. A., Sturge-Apple, M., \& Cicchetti, D. (2009). Maternal depression, children's attachment security, and representational development: An organizational perspective. Child Development, 80, 192 208.

Turton, P., Hughes, P., Fonagy, P., \& Fainman, D. (2004). An investigation into the possible overlap between PTSD and unresolved responses following stillbirth: An absence of linkage with only unresolved status predicting infant disorganization. Attachment \& Human Development, 6, 241-253.

Ursano, R. J., Fullerton, C. S., Epstein, R. S., Crowley, B. Vance, K., Kao, T.C., et al. (1999). Peritraumatic dissociation and posttraumatic stress disorder following motor vehicle accidents. American Journal of Psychiatry, 156, 1808-1810.

Valente, N. L. M., Vallada, H., Cordeiro, Q., Bressan, R. A., Andreoli, S. B., Mari, J. J., et al. (2011). Catechol- $O$-methyltransferase (COMT) val158met polymorphism as a risk factor for PTSD after urban violence. Journal of Molecular Neuroscience, 43, 516-523.

van IJzendoorn, M. H. (1995). Adult attachment representations, parental responsiveness, and infant attachment: A meta-analysis on the predictive validity of the Adult Attachment Interview. Psychological Bulletin, $117,387-403$.

van IJzendoorn, M. H., \& Bakermans-Kranenburg, M. J. (2006). DRD4 7-repeat polymorphism moderates the association between maternal unresolved loss or trauma and infant disorganization. Attachment \& Human Development, 8, 291-307. 
van IJzendoorn, M. H., Schuengel, C., \& Bakermans-Kranenburg, M. J. (1999). Disorganized attachment in early childhood: Meta-analysis of precursors, concomitants, and sequelae. Development and Psychopathology, 11, 225-249.

Vaughn, B., Waters, E., Egeland, B., \& Sroufe, L. A. (1979). Individual differences in infant-mother attachment at 12 and 18 months: Stability and change in families under stress. Child Development, 50, 971-975.

Wakschlag, L. S., Pickett, K. E., Cook, E. J., Benowitz, N. L., \& Leventhal, B. L. (2002). Maternal smoking during pregnancy and severe antisocial behavior in offspring: A review. American Journal of Public Health, 92, 966-974.

Wan, M. W., \& Green, J. (2009). The impact of maternal psychopathology on child-mother attachment. Archives of Women's Mental Health, 12, 123-134.

Warren, S. L., Huston, L., Egeland, B., \& Sroufe, L. A. (1997). Child and adolescent anxiety disorders and early attachment. Journal of the Academy of Child and Adolescent Psychiatry, 36, 637-644.

Weathers, F. W., Huska, J. A., \& Keane, T. M. (1991). The PTSD ChecklistCivilian version $(P C L-C)$. Unpublished manuscript. Available from F. W. Weathers, National Center for PTSD, Boston Veterans Affairs Medical Center.

Weathers, F. W., Keane, T. M., \& Davidson, J. R. (2001). Clinician-Administered PTSD Scale: A review of the first ten years of research. Depression and Anxiety, 13, 132-156.

Weaver, I. C. G., Meaney, M. J., \& Szyf, M. (2006). Maternal care effects on the hippocampus transcriptome and anxiety-mediated behaviors in the offspring that are reversible in adulthood. Proceedings of the National Academy of Sciences, 103, 3480-3485.

Wechsler, D. (1967). Manual for the Wechsler Preschool and Primary Scale of Intelligence. San Antonio, TX: Psychological Corporation.

Wechsler, D. (1974). Manual for the Wechsler Intelligence Scale for Children-Revised. San Antonio, TX: Psychological Corporation.

Werner, K. B., \& Griffin, M. G. (2012). Peritraumatic and persistent dissociation as predictors of PTSD symptoms in a female cohort. Journal of Traumatic Stress, 25, 401-407.

White, R. F., Campbell, R., Echeverria, D., Knox, S. S., \& Janulewicz, P. (2009). Assessment of neuropsychological trajectories in longitudinal population-based studies of children. Journal of Epidemiology and Community Health, 63(Suppl. I), i15-i26.
Wolfe, J., \& Kimerling, R. (1997). Gender issues in the assessment of posttraumatic stress disorder. In J. P. Wilson \& T. M. Keane (Eds.), Assessing psychological trauma and PTSD (pp. 192-238). New York: Guilford Press.

Wright, R. J., Suglia, S. F., Levy, J., Fortun, K., Shields, A., Subramanian, S. V., et al. (2008). Transdisciplinary research strategies for understanding socially patterned disease: The Asthma Coalition on Community, Environment, and Social Stress (ACCESS) project as a case study. Ciencia Saude Coletiva, 13, 1729-1742.

Yehuda, R., Bell, A., Bierer, L. M., \& Schmeidler, J. (2008). Maternal, not paternal, PTSD is related to increased risk for PTSD in offspring of Holocaust survivors. Journal of Psychiatric Research, 42, 1104-1111.

Yehuda, R., \& Bierer, L. M. (2008). Transgenerational transmission of cortisol and PTSD risk. Progress in Brain Research, 167, 121-134.

Yehuda, R., Engel, S. M., Brand, S. R., Seckl, J., Marcus, S. M., \& Berkowitz, G. S. (2005). Transgenerational effects of posttraumatic stress disorder in babies of mothers exposed to the World Trade Center attacks during pregnancy. Journal of Clinical Endocrinology \& Metabolism, 90, 4115-4118.

Yehuda, R., Halligan, S. L., \& Bierer, L. M. (2001). Relationship of parental trauma exposure and PTSD to PTSD, depressive and anxiety disorders in offspring. Journal of Psychiatric Research, 35, 261-270.

Yehuda, R., Halligan, S. L., \& Grossman, R. (2001). Childhood trauma and risk of PTSD: Relationship to intergenerational effects of trauma, parenta PTSD, and cortisol excretion. Development and Psychopathology, 13, 733-753.

Yehuda, R., Schmeidler, J., Giller, Jr., E. L., Siever, L. J., \& Binder-Brynes, K. (1998). Relationship between posttraumatic stress disorder characteristics of Holocaust survivors and their adult offspring. American Journal of Psychiatry, 155, 841-843.

Yehuda, R., Schmeidler, J., Wainberg, M., Binder-Brynes, K., \& Duvdevani, T. (1998). Vulnerability to posttraumatic stress disorder in adult offspring of Holocaust survivors. American Journal of Psychiatry, 155, 11631171.

Zeanah, C. H., Danis, B., Hirshberg, L., Benoit, D., Miller, D., \& Heller, S. S. (1999). Disorganized attachment association with partner violence: A research note. Infant Mental Health Journal, 20, 77-86. 